Florida International University

FIU Digital Commons

3-27-2019

\title{
The Development and Validation of the M.A.W.W.: A Measure to Assess Men's Allyhood toward Women in the Workplace
}

\author{
Edward J. Sullivan \\ Florida International University, esull016@fiu.edu
}

Follow this and additional works at: https://digitalcommons.fiu.edu/etd

Part of the Industrial and Organizational Psychology Commons

\section{Recommended Citation \\ Sullivan, Edward J., "The Development and Validation of the M.A.W.W.: A Measure to Assess Men's Allyhood toward Women in the Workplace" (2019). FIU Electronic Theses and Dissertations. 3965. https://digitalcommons.fiu.edu/etd/3965}

This work is brought to you for free and open access by the University Graduate School at FIU Digital Commons. It has been accepted for inclusion in FIU Electronic Theses and Dissertations by an authorized administrator of FIU Digital Commons. For more information, please contact dcc@fiu.edu. 


\section{FLORIDA INTERNATIONAL UNIVERSITY}

Miami, Florida

\section{THE DEVELOPMENT AND VALIDATION OF THE M.A.W.W.: A MEASURE TO} ASSESS MEN'S ALLYHOOD TOWARD WOMEN IN THE WORKPLACE

A dissertation submitted in partial fulfillment of the

requirements for the degree of

DOCTOR OF PHILOSOPHY

in

PSYCHOLOGY

by

Edward Joseph Sullivan 
To: Dean Michael R. Heithaus

College of Arts, Sciences and Education

This dissertation, written by Edward Joseph Sullivan, and entitled The Development and Validation of the M.A.W.W.: A Measure to Assess Men's Allyhood toward Women in the Workplace, having been approved in respect to style and intellectual content, is referred to you for judgment.

We have read this dissertation and recommend that it be approved.

Valentina Bruk-Lee

Thomas Reio

Dionne Stephens

Asia Eaton, Major Professor

Date of Defense: March 27, 2019

The dissertation of Edward Joseph Sullivan is approved.

Dean Michael R. Heithaus College of Arts, Sciences and Education

Andrés G. Gil

Vice President for Research and Economic Development and Dean of the University Graduate School

Florida International University, 2019 
(C) Copyright 2019 by Edward Joseph Sullivan

All rights reserved. 


\section{ACKNOWLEDGMENTS}

This dissertation represents not just the idea, analysis, and manifestation of a research project, but it is a symbol of the tremendous sacrifice that my husband has made to afford me the opportunity to go back to school later in my life to pursue a personal and professional goal. In short, my pursuit of excellence and expertise in Industrial and Organizational Psychology (I/O) would not be possible without the love and support of Merin David Newman. Thank you, David for making my educational experience never seem like a burden upon you, although at times, I am sure it truly was. Thank you, for your boundless encouragement and for picking up the torch to lead the way when I was confused and lost. Here, I publicly acknowledge your overwhelming contribution to this project and to my entire postgraduate experience. I love you.

I would also like to acknowledge the unending support and mentorship of Dr. Asia Eaton, my major professor, role model, and friend. Without Dr. Eaton's academic guidance and scholarship, this project would not be possible. Thank you, Dr. Eaton for praising my strengths and for challenging my weaknesses. Your passion for social justice through scholarship inspires me to be not just a more competent researcher and academician, but a better human being.

I want to also express gratitude to my dissertation committee: Dr. Valentina Bruk Lee, Dr. Thomas Reio, and Dr. Dionne Stephens. Your flexibility, insight, and dedication to this long term project made the whole endeavor that much more meaningful and rewarding. I would also like to thank Dr. Chockalingam Viswesvaran, leader of Florida International University's I/O program, for welcoming me into the program and making my dream to pursue a second chapter in my academic career possible. 


\section{ABSTRACT OF THE DISSERTATION}

\section{THE DEVELOPMENT AND VALIDATION OF THE M.A.W.W.: A MEASURE TO ASSESS MEN'S ALLYHOOD TOWARD WOMEN IN THE WORKPLACE}

by

Edward Joseph Sullivan

Florida International University, 2019

Miami, Florida

\section{Professor Asia Eaton, Major Professor}

In the workplace, women can experience stereotyping and marginalization as a result of their gender (Eagly \& Carli, 2007; Gipson, Pfaff, Mendelsohn, Catenacci, \& Burke, 2017). Having allies, or people who are supportive of or who advocate for an oppressed group can help members of marginalized communities to achieve personal and social success (Drury, 2014; Evans \& Washington, 1991). The Men's Allyhood toward Women in the Workplace (M.A.W.W.) measure seeks to evaluate men's supportiveness of women in the workplace, enabling researchers and practitioners to understand and improve the climate for women at work. The M.A.W.W. was first developed with the input of five subject matter experts who commented on the clarity and relevance of a list of 84 proposed items. The item pool was pared down from 84 items to 59 which were then subjected to an exploratory factor analysis. The exploratory factor analysis narrowed the item pool from 59 to seventeen items. Although it was hypothesized that the M.A.W.W. would yield six factors, only three factors were supported by the analysis: Knowledge \& Awareness, Action, and Skills \& Capacity. These three factors showed internal consistency reliabilities that ranged from acceptable to excellent. A confirmatory 
factor analysis then led to the deletion of two more items, yielding a total of fifteen items for the final, three-factor version of the M.A.W.W. Convergent validity of this final measure was demonstrated by positive correlations with scales assessing affirming attitudes toward women in general. Evidence of divergent validity was shown with negative correlations with scales assessing negative and prejudicial attitudes against women. Furthermore, construct evidence was demonstrated with statistical analysis showing no correlation between the M.A.W.W. and a personality scale. 


\section{TABLE OF CONTENTS}

CHAPTER

1

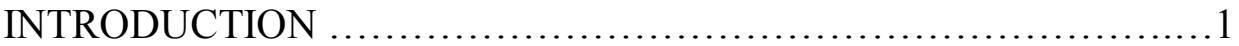

Gender in Organizations................................................ 2

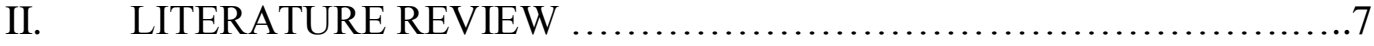

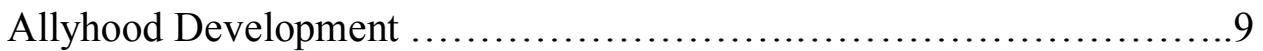

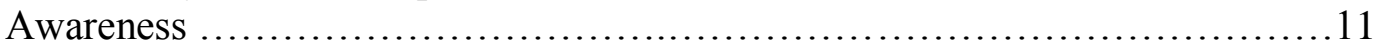

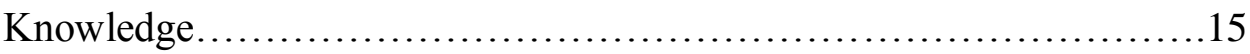

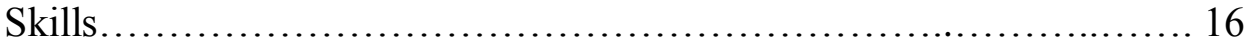

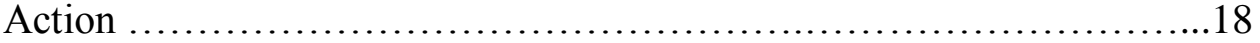

III. PRESENT STUDY ............................................... 18

M.A.W.W. Dimensions 1 and 2: Distal and Proximal

Awareness............................................................ 19

M.A.W.W. Dimensions 3: Knowledge...............................21

M.A.W.W. Dimensions 4 and 5: Skills.......................................22

M.A.W.W. Dimensions 6: Action....................................22

IV. STUDY I. THE DEVELOPMENT AND INITIAL PSYCHOMETRIC EVALUATION OF THE MA.W.W................24

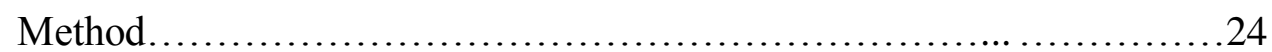

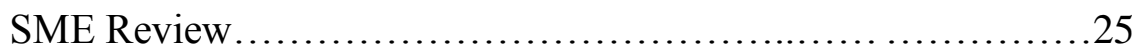

Exploratory Factor Analysis.................................27

Best Factor Solution..................................29

Exploratory Factor Results.................................. 30

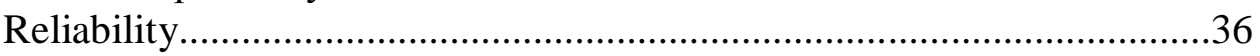

V. STUDY II. CONFIRMATION OF THE M.A.W.W. .....................37

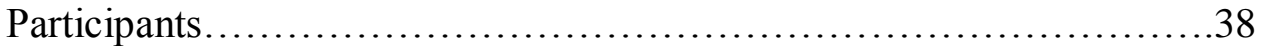

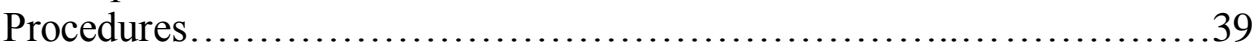

Confirmatory Factor Analysis...................................39

Confirmatory Factor Analysis Results...............................40

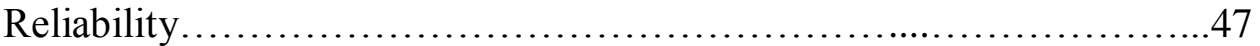

VI. STUDY III. ASSESSMENT OF THE VALIDITY OF

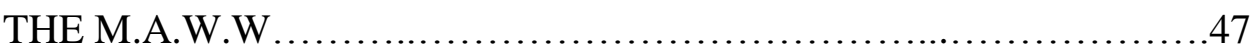

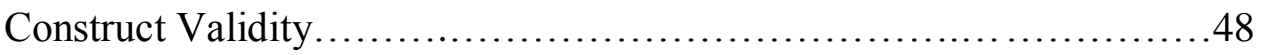

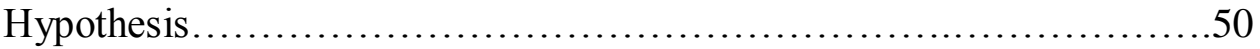

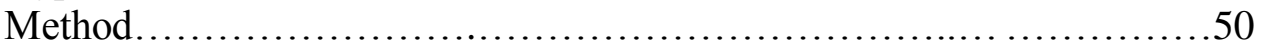


Instruments..................................................51

Men's Allyhood toward Women in the Workplace................51

Attitude toward Women Scale.................................51

Neosexim Scale...........................................52

Social Dominance Scale...........................................52

Humanitarian Egalitarian..................................53

Ambivalent Sexism Inventory .............................53

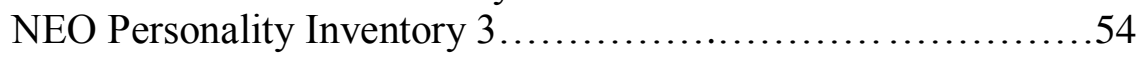

Demographics...................................................... 55

Results......................................................56

Tenure, Age, and Political Affiliation..........................59

Political Affiliation and the M.A.W.W. Factors................60

Male Managers and Percentage of Women

Supervised..............................................61

Pattern Invariance...............................................61

VII. DISCUSSION ................................................62

VIII. LIMITATIONS AND DIRECTIONS FOR FUTURE

RESEARCH..................................................69

Limitations....................................................69

Directions for Future Research...................................... 70

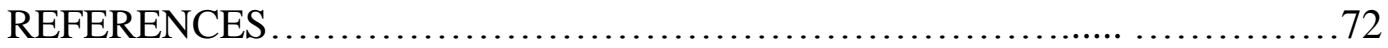

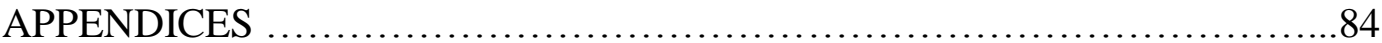

VITA............................................................... 100 


\section{LIST OF TABLES}

TABLE

1. Exploratory Factor Analysis Factor Loadings.............................. 35

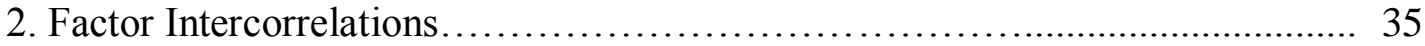

3. Skewness and Kurtosis of Fifteen Items in the Final M.A.W.W .............. 42

4. Confirmatory Factor Analysis Loadings for M.A.W.W. Items................ 44

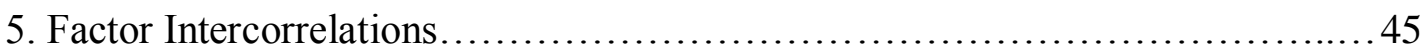

6. Internal Consistency Reliability, Convergent, and Divergent Validity for

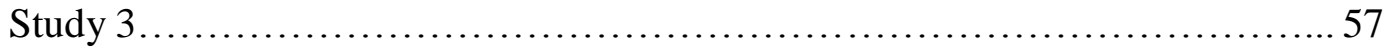

7. Correlations of Key Demographics with the M.A.W.W..................... 58

8. Multiple Regression Analysis of Three Predictors of

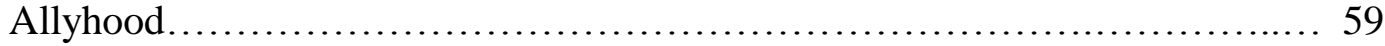




\section{INTRODUCTION}

Since World War II women's participation in the workforce has steadily increased (U.S. Department of Labor, 2018). Current estimates now report that women represent $58.1 \%$ of the modern U.S. workforce, and have held the majority of workforce participation for the last decade (U.S. Department of Labor, 2018). Additionally, 59\% of women work full-time and year-round, compared to $40 \%$ in 1970 (U.S. Department of Labor, 2018), and are obtaining education to propel their careers, with women today being more likely than men to earn a high school diploma, a post-secondary degree, and even an advanced graduate degree (Leslie, Manchester, \& Dahm, 2017; U.S. Department of Labor, 2018). Yet despite these efforts towards equality, the salaries and rankings of women in organizations lag behind those of men (Proctor, Semega, \& Kollar, 2016). On the basis of annual salary earnings, women are paid $78 \%-82 \%$ of what men are paid and they are greatly underrepresented in leadership and management roles (U.S. Bureau of Labor Statistics, 2018).

The reasons for these gender disparities at work have been the subject of considerable research and conjecture. Some explanations are discussed in terms of external barriers to the advancement of women in the workplace - gender stereotypes and bias, prejudice, and discrimination (Eagly \& Carli, 2007; Gipson, Pfaff, Mendelsohn, Catenacci, \& Burke, 2017). In general, explanations along these lines suggest and demonstrate that societal, structural, and cultural factors, significantly impede women's career development and success (e.g., Correll, Benard, \& Paik, 2007; Eagly \& Karau, 2002; Heilman, 2012). Other explanations for the existence of workplace differences between women and men are discussed in terms of women's internal attributes such as 
their preferences, values, needs and goals (e.g., Diekman, Brown, Johnston, \& Clark, 2010). For example, one explanation from this set for why women earn less than men is because women purposefully self-select into lower paying jobs as a tradeoff for some other benefit, like flextime or predictable hours (Barbulescu \& Bidwell, 2013). Although these explanations and discussions regarding gendered workplace disparity may have different points of origin, they are likely interconnected and bidirectional (Joshi, Son, \& Roh, 2015; Wright, Eaton, \& Skagerberg, 2015) as in the case of a woman who intentionally exits a traditionally male-dominated field of employment where gender bias is high.

\section{Gender in Organizations}

In adherence with social-cultural explanations, researchers and practitioners typically use an organizational framework to interrogate and solve gender disparities at work (e.g., Kossek, Su, \& Wu, 2017). An organizational approach to understanding gender disparities considers the workplace forces and circumstances that impact women employees such as selection and promotion policies and practices, job design, and organizational communications (Kossek et al., 2017). One organizational influence that leads to gender disparities is bias against women by coworkers, managers, subordinates, and customers. In an employment context, bias against women is when women are not associated with the abilities and traits required for particular roles, and therefore are deemed less likely to be qualified for or successful in those roles as compared to men (Eagly \& Karau, 2002). When a job role calls for agentic qualities, such as being dominant, ambitious, or assertive, a woman is typically viewed as a poor fit because these qualities are more traditionally associated with a man (Eagly, 2013; Heilman, 2012). Bias 
in this context leads to a loss of job opportunity and/or promotion for women and causes gendered disparity at work (Eagly, 2013; Heilman, 2012). Furthermore, in those cases where women do exhibit traditionally held male qualities, they often face bias in the form of "backlash," a negative reaction from external forces such as coworkers, managers, and customers for role incongruent behaviors (Kossek et al., 2017; Phelan \& Rudman, 2010; Williams \& Tienden, 2016). Bias and backlash are of chief concern for the advancement of women because even though they are more pronounced in male-dominated industries and leadership roles, they stretch across all stages of women's career development and occupations (Kossek et al., 2017; Paustian-Underdahl, Eaton, Mandeville, \& Little, in press; Phelan \& Rudman, 2010).

One solution to address gender disparities at work involves making structural changes, such as changes to organizational climate. Generally, organizational climate is defined as organizational members' shared perceptions of aspects of the organization, with an emphasis on perceptions of the social environment, such as employment practices, policies, and events (Denison, 1996; Schneider, Erhart, \& Macey, 2013). Organizational climate is rooted in the deep structures and values of organizations, including the attitudes, opinions, and beliefs of employees and leaders (Denison, 1996; Schneider et al., 2013), and has been the focus of a great deal of research as it relates to women and their work experiences. Over the years, researchers have studied organizational climate as a moderator of the relationship between diversity and organizational performance (e.g., Gonzalez \& DeNisi, 2009), as a mediator through which leadership exerts its impact on employees (e.g., Dragoni, 2005), and as a 
foundational component of organizational structures like employment practices and company resources (e.g., Schneider et al., 1998).

Kossek and colleagues (2017) suggest that organizational efforts to reshape the workplace climate, including workers' attitudes and beliefs in support of working women, would have the effect of reducing bias against women employees. Yet, to make changes to employee's attitudes and beliefs, it is imperative to understand what those attitudes are. The purpose of this dissertation is to develop and validate a tool that will measure the attitudes and beliefs of men in the workforce as they relate to the equal treatment of women at work. Such a tool will have practical benefits for practitioners and academic researchers alike.

Although multiple validated and reliable scales assess people's attitudes and beliefs about women, no measure to date has specifically sought to identify how supportive men are of women in the workplace. For example, the Attitude towards Women Scale (Spence \& Hahn, 1997; Spence \& Helmreich, 1972) and the Ambivalent Sexism Inventory (Glick \& Fiske, 1997) both measure general, global assessments of gender-role attitudes and beliefs. Sample items from the Attitudes towards Women Scale include "Swearing and obscenity are more repulsive in the speech of a woman than a man" and "A woman should be as free as a man to propose marriage" (Spence \& Hahn, 1997), and sample items from the Ambivalent Sexism Inventory include "In a disaster, women ought not necessarily to be rescued before men" and "Most women interpret innocent remarks or acts as being sexist" (Glick \& Fiske, 1997). While both scales each include a small number of questions about men's and women's work roles, they do not systematically assess the varied ways working individuals can support and be allies to 
working women, nor do they constitute a separate dimension of the assessments. For example, the item, "under modern economic conditions with women being active outside the home, men should share in household tasks such as washing dishes and doing laundry" from the Attitudes towards Women Scale (Spence \& Hahn, 1997, p. 7) assesses participant's views about the gendered division of labor rather than directly gauging the participant's direct level of support for women at work.

Unlike these two scales, the Sex Role Egalitarian Scale (Beere, King, Beere, \& King, 1984) does contain a full dimension that relates to the workplace. However, the items in this dimension are designed to assess beliefs about gender equality at work rather than elements of allyhood, such as the item "a male nurse cannot be as effective as a female nurse" (p. 567). In addition, these workplace questions constitute a very small part of the inventory, being less than $20 \%$ of the total number of items (Beere et al., 1984).

By better understanding men's attitudes, beliefs, and behaviors regarding support for women at work, practitioners and researchers will be able to more clearly and adeptly create and implement developmental and educational programs and practices. For practitioners looking to improve their organization's climate for women and lessen gendered disparities at work, a measure such as the M.A.W.W. can be used to determine whether the aggregate identity of their workforce requires developmental programs such as workshops or training sessions that are geared towards fostering support for womenwhether these programs are designed to educate men as to the existence of gendered disparities at work or a slightly more nuanced approach that informs men of specific ways they can assist and support women in succeeding at work. In addition to learning and development opportunities, a device to identify allies of women at work would be 
vital in measuring the effectiveness of these programs, as well as assessing the impact of other changes on the organizational climate.

Another organizational influence that affects gender disparities at work is the imbalance in the quantity and quality of career resources, such as social networks, mentoring, and sponsorship (Michailidis, Morphitou, \& Theophylatou, 2012), and a tool such as the M.A.W.W. could have some utility in narrowing these disparities. For example, women often receive psychological support from superiors whereas men receive career development support (Wanberg, Welsh, \& Hezlett, 2003). Organizations that seek to reexamine the benefits women are deriving from their mentoring and sponsorship programs (Kossek et al., 2017) could use a tool like the M.A.W.W. to identify those allies who may best serve in a mentoring or sponsorship role for women. Academic researchers will also benefit from the M.A.W.W., as it will enable research on the antecedents, correlates, and consequences of allyhood for individuals, groups, and organizations. Measures that accurately capture individual differences in complicated, developmental constructs afford researchers the opportunity to conduct broad quantitative studies (Jones, 2014). One example of the utility of the M.A.W.W. measure involves addressing the factors that enable women to succeed in leadership positions at work (King, Hebl, George, \& Matusik, 2010). With the ability to identify allies of women in the workplace, researchers could quantifiably determine the extent to which internal allies can offset or eliminate some of the challenges women leaders face, such as backlash in negotiation or evaluation (Amanatullah \& Morris, 2010; Bowles, Babcock, \& Lai, 2007; Rudman \& Glick, 2001). Given the potentially far-reaching 
implications and utility of the M.A.W.W., it is first important to understand what constitutes an ally, what functions allies perform, and how they may be developed.

\section{LITERATURE REVIEW}

Various definitions have been used to understand the nature of individuals who are supportive of the experiences and well-being of outgroup members. Washington and Evans (1991) defined allies as individuals who are a "member of the dominant or majority group who work to end oppression in their personal and professional life through support of, and as advocates with and for, the oppressed population" (p. 313). Building upon Washington and Evans (1991), Broido (2000) defined allies as "members of dominant social groups (e.g., men, Whites, heterosexuals) who are working to end the system of oppression that gives them greater privilege and power based on their social group membership" (p. 3). In this social grouping context, allies are individuals who belong to a particular group different than the oppressed group, and who seek to challenge power structures that provide the allies themselves with privilege and benefits. Privilege, meanwhile, is generally understood to mean unearned benefits or advantages that members of the ingroup enjoy (Case, Hensley, \& Anderson, 2014; Edwards, 2006; McIntosh, 2001; Reason, Scales, \& Millar, 2005), and oppression often refers to the systematic phenomenon of ideological domination and institutional control by the ingroup in its exploitation of the outgroup for its own benefit (Case, Hensley, \& Anderson, 2014; Edwards, 2006; Reynolds \& Pope, 1991; Hardaman \& Jackson, 1982). Scholars generally agree that privilege and oppression occur whether or not an individual ingroup member is consciously aware of these forces, and whether or not the ingroup members recognize that they are the beneficiaries of privilege and oppression (Hardaman 
\& Jackson, 1982; David \& Wagner, 2005). Other scholars also emphasize the idea that allies work toward resisting and dismantling a system, and the system is one from which they benefit (e.g., Ayvazian, 1995; Mio \& Roades, 2003; Munin \& Speight, 2010).

Allies play a vital role in the struggle for equality and global liberation. As members of the dominant, privileged group, allies have access to knowledge, skills, and resources that are effective tools in reducing or eliminating oppression (Munin \& Speight, 2010). One prominent way allies can effectively support the oppressed group is through influencing their fellow ingroup members. Because of ingroup similarities that often bolster credibility, ingroup members frequently yield a greater degree of influence over other ingroup members, more so on many occasions than the degree of influence that an outgroup member would have (Petty \& Cacioppo, 1981; Petty et al., 2005). Understanding how allies span the boundaries between groups is important because oppression is hierarchical in nature, essentially a division occurring between ingroup members as privileged and outgroup members as oppressed (Bell, 2007). From this division comes privileges for the dominant ingroup members, reinforcing the incentive to maintain the division (Bell, 2007).

Despite these privileges, groups of allies have collaborated with oppressed populations in various struggles for equality throughout recent modern history. In the late 1800s, for example, men had sole access to the political system in the U.S. The role of male allies in supporting the women's suffrage movement was critical to eliminating gendered voter inequality (Stokes Brown, 2002; Zinn, 2003), because, as often is the case, the struggle for equality required a change in the voting laws through the political system (Stokes Brown, 2002). Other points in history have also seen prominent displays 
of allies supporting and promoting oppressed groups. In the 1960s Whites worked with Blacks for various civil and employment rights, and in the 1990s heterosexuals worked with LGBTQ members for the right to marry (Zinn, 2003), and these alliances are hypothesized to have made critical difference in the results that were obtained from these efforts (e.g., Cohen \& Zelnick, 2002), partly because of the majority group's command over political influence and resources (Jones, 2014).

\section{Allyhood Development}

To aid in the understanding of allyhood development, several models have been proposed over the years. Despite their conceptual and process differences, these models generally strive to answer the same basic questions: what constitutes an ally, and what role do allies perform towards the goal of achieving social justice equality? Allyhood development models, their common factors, and their evolution in the social justice literature, serve as the theoretical foundation for the development and validation of the M.A.W.W. Allyhood development models usually take one of two forms: stage models or factor models. A stage model suggests that allies move from some nascent entry level to an intermediate level(s) and finally becoming allies in the final stage (Bishop, 2002). Stage models of allyhood development find their origins primarily in university settings where social justice counselors have looked to develop and improve programs that shepherd students through diversity courses or workshop sessions. Factor models emerged as social justice theorist began to look for ways to translate group specific models for use with other groups. For instance, Broido (2000) referenced the stage racerelated model of Hardiman \& Jackson (1992) in order to develop an LGBTQ-related 
model and, in so doing, focused on the common factors between the two to justify the cross application.

One prominent stage model is Bishop's (2002) Allyhood Development Model, which describes allies as progressing in a step-wise fashion through six separate stages. The first stage of allyhood is for the individual to understand oppression and how it operates. To reduce or eliminate oppression, according to Bishop (2002), an ally must first examine internally his role as an oppressor, and how he has benefitted from oppression of the outgroup. The second stage of allyhood development involves understanding how an individual's social identity may intersect in some way with an oppressed population, but diverges on matters of power and privilege. The third step of Bishop's model (2002) allows for the healing of the pain caused when individuals realize the impact of their roles as oppressor and oppressed. This healing process leads to the to the fourth stage where individuals work towards their own liberation and marks the transition from conscious raising and healing to action as an ally. The fifth stage of this model is relatively broad and calls for the individuals to have an understanding of the oppressed population and its history, social structures, and a strategy to move forward, to name a few characteristics. The sixth and final stage of Bishop (2002) is taking action to reduce or eliminate oppression. This final stage generally calls upon the learning experiences and strategies developed in the fifth stage to effect social change.

By way of comparison, Broido (2000)'s Empirical Allyhood Development model provided a factor based model. Unlike a stage model, Broido's model (2000) focused on the characteristics and behaviors of an ally regardless of what processes, in what order, lead to their development of relevant attributes. Broido (2000) highlighted the following 
characteristics and behaviors: gathering information, making meaning of that information, and acquiring knowledge for the sake of taking action with regards to a social justice issue. The gathering information behavior refers to the individual's efforts to understand the perspective of members of the oppressed population. The meaning making component involves the process of individuals understanding that a system of oppression exists, and they play a role in that system. The knowledge for the sake of action component refers to acquiring facts and data so that individuals can prepare themselves for possible discussions with ingroup members regarding social justice issues. Additionally, Broido (2000) is a nonlinear factor model — in sharp contrast to the stage models. In a factor model, an individual may be partially or fully developed as an ally across any combination of factors, and may develop characteristics in any order. For instance, in Broido's (2000) model, an individual may be gaining knowledge regarding the history of women's civil rights movement, but still may not have made meaning of their personal role in a society that oppresses women.

\section{Awareness}

One common theme that emerges from both Broido's (2000) and Bishop's (2002) models of allyhood is the concept of awareness. This awareness concept is echoed in allyhood development models subsequently offered by additional theorists. Reason, Scales, and Millar (2005) focused on the concept of ally awareness in their model and introduced two forms of ally awareness for understanding allyhood development: intellectual awareness and emotional awareness of oppression, power, and privilege. An intellectual understanding of oppression, power, and privilege refers to being aware of the large, systematic forces that produce social injustices, and inequalities between the 
ingroup and outgroup. Both ingroup and outgroup members exist within an entire system where contextual forces shape unequal outcomes (Reason, et al., 2005, citing Bishop, 2002). In comparison, an emotional understanding involves a personal realization and acceptance by ingroup members that they benefit in some way from the oppression, power, and privilege. Reason et al., (2005) theorized that increasing ally awareness, whether intellectual or emotional, corresponds with an increasing likelihood that privilege-cognizant allies will draw upon their pro-social justice attitudes and take outward action to support outgroup members in the quest for social equality.

Similar to Reason et al., (2005), Edwards (2006) put forth an allyhood development model that featured ally awareness as a central component. Edwards (2006) categorized ingroup members' allyhood development on the basis of their underlying motivations. Edwards (2006) devised three categories of allyhood development: ally for self - interest, ally for altruism, and ally for social justice. An ally for self-interest is primarily concerned with protecting those that they care about. In this regard, allies for self-interest are motivated by a desire to seek social equality not because of a broader opposition to the systematic forces that create inequities between groups, but because they want to end the suffering of loved ones that comes from unfair social outcomes. Although self-interested allies may seek change in immediate and nearby circumstances that affect them through the experiences of their loved ones, they are in favor of maintaining the status quo of societal structures, assuming they are even aware of the larger, more contextual forces like ingroup privilege.

Allies for altruism, however, are cognizant of ingroup privilege, but only to the extent that it exists in a systematic, generalized way. Allies for altruism are motivated by 
the ingroup guilt associated with their realization that ingroup privilege exists (Edwards, 2006). Their support for outgroup members is an expression of their desire to alleviate that guilt and make right for past wrongs. While recognizing that ingroup privilege exists, allies for altruism try to personally distance themselves from the notion that they may be the beneficiaries of ingroup privilege (Edwards, 2006). In comparison, allies for social justice are motivated by a desire to make an impact for both ingroup and outgroup members as they view the whole of society as victims to ingroup privilege - themselves included. Social justice allies recognize that unearned power and privilege are detrimental to the privileged as well as the oppressed, and hinder genuine and meaningful relationships between ingroup and outgroup members (Goodman, 2011). In other words, although allies for social justice may recognize that outgroup members suffer more in kind and degree than ingroup members, they find the prospect of social equality to be personally liberating in that it grants more meaningful and genuine relationships with other humans.

In addition to building upon prior work to expand or fine-tune allyhood development models, concepts, and definitions, scholars have begun to synthesize these models to formulate a more unified approach to understanding allyhood. Waters (2010) presented an allyhood model with three nonlinear categories that ingroup members can occupy. Within these categories ingroup members may develop at different rates, being fully developed in one category and partially developed in another, for instance. Although in the Waters' (2010) model, ingroup members transition from an initial stage, to an intermediate stage, and finally to a mature ally stage, they move in and out of each category in a nonlinear fashion. In essence, Waters (2010) proposed a factor model with 
stage model features. Specifically, Waters (2010) proposed three categorical processes of allyhood development, of which one is "intrapersonal," reflecting the degree of selfawareness an individual has in relation to their peers. Akin to Edwards' (2006) intellectual and emotional states of awareness, ingroup members transition from the initial stage of unawareness or an awareness that is self-centered, to an intermediate stage of awareness that involves an abstract understanding of circumstances that are external to themselves, to finally, a more mature state of complete internal awareness of privilege and how they factor into the societal system. Waters' (2010) final process of allyhood development, "interpersonal," builds upon the concept of action as discussed in Broido (2000) and Reason et al., (2005). A fully mature interpersonal ingroup member would have the capacity to engage in meaningful relationships with outgroup members as well as take action to end ingroup privilege and oppression (Waters, 2010).

Although Broido (2000), Bishop (2002), Reason et al., (2005), and Waters (2010) are models of racial and LGBTQ allyhood, they are also relevant to issues involving women. In terms of allyhood toward women, men's awareness that their identity and life experiences are different from those of women, and that these differences are shaped by a patriarchal system from which they benefit, parallel the two forms of awareness in the Reason et al., (2005) model. . A patriarchal system is the societal oppression of women by men which effectively inures benefits to men as members of the ingroup at the expense of women as members of the outgroup (Eagly \& Carli, 2007). Men who possess an awareness that a patriarchy exists, and that men as members of the ingroup are beneficiaries of this system, are more apt to recognize that women in general are oppressed and that women operate in the workplace at a disadvantage as compared to 
men (Davis \& Wagner, 2005). Davis and Wagner (2005) discussed how achieving this awareness is hindered by the patriarchal system itself because as the beneficiaries of this systematic oppression, men are rewarded for ignoring its existence. By ignoring the existence of the patriarchy, men maintain the status quo, and therefore, maintain the flow of privileges that come with it. Moreover, because these privileges are systematic and institutionalized, they often go unnoticed. Just as awareness of a system of raciallyrelated oppression is part of Whites' allyhood development in Waters (2010)'s race model, so too is the recognition of a patriarchal system and how it operates towards allyhood development for men as allies of women at work (Davis \& Wagner, 2005). An ally by definition joins with women in the effort to reduce or eliminate workplace inequities, but if he does not see the inequities caused by a patriarchal system, then he sees nothing that needs to be changed (Bishop, 2002) and will not be motivated to serve as an ally (Davis \& Wagner, 2005).

\section{Knowledge}

Another factor emerging from Broido (2000), and upon which scholars have subsequently built (e.g., Smith \& Redington, 2010), is the dimension of knowledgeacquiring facts and information regarding outgroup members' experiences. Without acquiring knowledge, including a general understanding of what outgroup members experience, ingroup members will not be motivated to take action to address social inequities (Getz \& Kirkley, 2003; Caldwell \& Vera, 2010; DiStefano, Croteau, Anderson, Kampa-Kokesch, \& Bullard, 2000; Smith \& Redington, 2010). Knowledge about an outgroup members' experiences can be acquired at workshops, training sessions (DiStefano et. al, 2000), informal group gatherings (Smith \& Redington, 2010), 
ingroup/outgroup intrapersonal exchanges (Washington \& Evans, 1991), and university class settings (Getz \& Kirkely, 2003).

Scholars have also drawn upon Broido's(2000) dimension of knowledge in furtherance of their own work, although not necessarily by name. For example, Waters (2010) fashioned the allyhood development process of "cognitive development" which refers to an ingroup member's capacity to understand cultural differences and the experiences of outgroup members. Ingroup members in the initial stage of cognitive development are relatively naïve as to this understanding whereas ingroup members in the mature stage are culturally informed and able to consider multiple perspectives objectively.

With regard to women, the allyhood development dimension of knowledge can refer to an individual's knowledge about laws, policies, practices, history, and cultural norms regarding women's efforts to achieve equality in a patriarchal society, as it is a vital component in understanding the experiences of women and the ways in which an ally can assist women (Broido 2000a; Washington \& Evans, 1991). Furthermore, as theorists have added, as knowledge increases it can lead to a rise in confidence which in turns further develops other dimensions of allyhood, such as skills (Jones, 2014).

\section{Skills}

In the social justice literature, another emerging component of allyhood development involves the skills of the ingroup member (e.g., Evans \& Washington, 1991). Skills are discussed in terms of the ingroup member's helping abilities, specifically to communicate to others about the outgroup member's identity and experiences (Washington \& Evans, 1991). In the context of work, helping behaviors are 
often referred to as "social support" (House, 1981; Sarafino, 2006; Semmer, Elfering, Jacobshagen, Perrot, Beehr, \& Boos, 2008). The seminal work of House (1981) from the organizational literature ushered in a model composed of four categories: emotional support, instrumental aid, informational assistance, and appraisal. In House's model (1981), emotional support involves affective characteristics like loving and caring. The instrumental aid category refers to a provision of services such as problem solving or the giving of resources, and the information assistance category includes counseling and advising. The last category, appraisal, combines assistance with the notion of selfevaluation in that supporters reflect upon their actions to learn how to act differently in future scenarios. Although there have been various adaptations of House's work, most models feature one or more of House's categories (Shakespeare-Finch \& Obst, 2011).

One adaptation of House's model reclassified the appraisal category as esteem support, the act of praising, and added a fifth classification of network support, which speaks to providing assistance that moves beyond the outgroup member into their larger network of contacts and resources (Caltabiano, Byrne, Martin \& Sarafino, 2002). Another variation returns to the four factor structure by combining emotional and esteem support and introducing companionship support, which includes a broader and more enduring relationship than emotional/esteem support (Sarafino, 2006). Yet throughout all these variations and adaptations, two forms of support have emerged as the most prominent and relevant: social/emotional support and instrumental support (Declercq, Vanheule, Markey, \& Willemsen, 2007). In essence, social/emotional support and instrumental support subsume all the other categories. For example, instrumental support subsumes 
information assistance because providing information is a service (Shakespeare-Finch \& Obst, 2008).

\section{Action}

A final common thread throughout most allyhood development models is the need for concrete action to dismantle oppression (Asta \& Vacha-Haase, 2013; Ayazian, 1995; Case, 2012; Mio \& Roades, 2003; Reynolds, 2010; Washington \& Evans, 1991). Because oppression is a system that allows access to benefits and privilege based upon group membership, it is only the action of individuals that brings about systematic change (Reynolds, 2010). In fact, some scholars have gone so far as to claim that anything short of a visible and overt act of support for the oppressed is a form of collusion furthering entrenching the system of oppression (Ayazian, 1995; Mio \& Roades, 2003; Reynolds, 2010). Other scholars have argued that numerous overt acts of support are required for individuals to qualify as allies, as the repetition is necessary to ensure that individuals to have sufficient personal experiences to internalize their role as allies (Bailey, 1998). The type of behavior that constitutes an act varies. Actions such as attending protests, advocating for outgroup members, displaying symbols, and dispelling myths are just a few examples of actions that are linked to allyhood development (DiStefano et al., 2000; Jones, 2014).

\section{THE PRESENT STUDY}

The present study represents three independent studies to develop and validate a scale. To examine men's allyhood toward women in the workplace, six dimensions of allyhood development were initially hypothesized and tested, using factors uncovered in the literature on allyhood across multiple disciplines. The attributes and behaviors that were 
initially hypothesized to undergird allyhood were: distal awareness, proximal awareness, knowledge, social support, instrumental support, and action. Although prior research has indicated that social support and instrumental support correlate highly (e.g., Semmer et al., 2008), this association does not mean that these concepts are identical, and they may operate differently under different contextual circumstances.

For the purposes of identifying allyhood toward women in the workplace, the following definition of an ally was adopted:

An ally is a man who is actively supporting and promoting the rights and wellbeing of women, helping to reduce or eliminate the barriers or inequalities that women face in the workplace.

\section{M.A.W.W. Dimensions 1 and 2: Distal and Proximal Awareness}

The first proposed dimension of the measure of Men's Allyhood towards Women in the Workplace (M.A.W.W.) was awareness. Scholars have discussed the dimension of ally awareness by focusing on two types. One type focuses on a level of awareness that is abstract and broad (Bishop, 2002; Edwards, 2006; Reason et al., 2005) - “distal awareness." In distal awareness, a man recognizes that a patriarchy exists and that men in general are its beneficiaries in the workplace (Bishop, 2002). Distal awareness refers to an ally's abstract understanding that the rights of men and women operate differently in a patriarchal system, and that men in general are the beneficiaries of this system at multiple levels in organizations(David \& Wagner, 2005). An example of a distal awareness item in the M.A.W.W. is "In general, women are not treated as favorably as men in the workplace." Without the dimension of distal awareness, a man would lack the necessary empathy and motivation to serve as an ally to women in the workplace (Davis \& Wagner, 
2005). In other words, if a man does not understand that a problem exists, he is unlikely to assist in implementing a solution.

The second type of awareness focuses on a level of recognition that is more personal and relates directly to the ally himself. This personal type of awareness is where a man recognizes that the patriarchy exists and that he himself is the beneficiary to some degree of this system (Edwards, 2006; Reason et al., 2005) - "proximal awareness." Such a proximal awareness of the effects of the patriarchy on women not only increases the likelihood that an ally will take steps to eliminate barriers to women in the workplace, but it also increases the likelihood that the ally will educate other ingroup members as to the deleterious effects of the patriarchal system on women in general and society as a whole (Jones, 2014). In the M.A.W.W., "I recognize that certain benefits at work may come more easily to me as compared to my female coworkers" is an example of a proximal awareness item. Proximal awareness involves a man's personal understanding and recognition that as a member of the ingroup, he himself is a beneficiary of the patriarchy to some degree (Reason et al., 2005). Proximal awareness as compared to distal awareness is more specific in nature and is directly related to the individual ally, and in so being proximal awareness requires a greater sense of self-awareness than distal awareness (Bishop, 2002), and it is this sense of self-awareness that is an essential component of allyhood. Although distal and proximal awareness are conceptually different, researchers have treated them as a single construct (e.g., Jones, 2014). This dissertation will use factor analysis to assess the extent to which distal and proximal awareness are separate constructs, allowing for the possibility that some men may be 
generally aware of women's experiences in a patriarchal society, but not aware that they themselves benefit from sexism.

\section{M.A.W.W. Dimension 3: Knowledge}

Of all the dimensions that contribute to allyhood development, "knowledge" seems to be the most clearly defined (Bishop, 2002; Edwards, 2006; Jones, 2014; Washington \& Evans, 1991; Waters, 2010). The proposed measure in the present study will seek to identify men who are allies of women at work by assessing their degree of knowledge of women's experiences as demonstrated through laws, policies, practices and cultural norms. For example, one proposed item is "I am familiar with a number of laws that give women protection from unequal treatment at work."

The knowledge dimension is distinct from the dimension of awareness. Conceivably, it is possible for a man to know that there are federal laws prohibiting gender disparity in pay for the same job, yet at the same time be unaware that such a law is necessary because of an ongoing system of oppression. Conversely, it is possible for a man to lack the knowledge that pay equality laws and remedies are available to women, but still be aware that women's experiences at work are shaped by sexism. Moreover, the dimension of knowledge is distinct from skills. Having knowledge of something does not necessarily mean having the ability or skill to act on it. For example, a man may know that women experience sexual harassment at work, but lack the ability to provide an empathetic ear to a woman victim of harassment. A knowledge item from the M.A.W.W. is "There was a time in our history where women were expected to quit their jobs when they got married." 


\section{M.A.W.W. Dimension 4 and 5: Skills}

The dimension of "skills" involves the skills and abilities an ally may possess in supporting women at work. Prior research has identified two skills in particular that are characteristics of an ally: social support and instrumental support. Social support refers to an ally's listening and empathy skills (Jones et al., 2014). An ally strong in this dimension would have well-developed interpersonal skills that demonstrate warmth and trustworthiness to a member of the outgroup. "I am willing to have an open discussion about women's workplace issues" represents a social support item in the M.A.W.W. Instrumental support, on the other hand, refers to an ally's ability to direct women to resources when asked (House, 1981). Having the ability to instrumentally support women who face sexism and sexist oppression in the workplace is an important feature male allies of women at work should possess. "If asked, I can direct a woman to outside resources (for example: books, Web sites, support groups, etc.) that support women's rights at work" represents an instrumental support item in the M.A.W.W.

Similar to the two forms of awareness, researchers have treated the two forms of support skills as a single construct (e.g., Jones et al., 2014). The present study will use factor analysis to explore the possibility that social support skills and instrumental support skills are distinct constructs, allowing for the possibility that some men may be capable of providing information about resources when called upon, yet may have underdeveloped empathy skills.

\section{M.A.W.W. Dimension 6: Action}

Although theorists are split on the intensity of action needed to be an ally (Stokes Brown, 2002; Zinn, 2003), it is an unquestionably important element of allyhood, and 
should be specific to a particular outgroup. Action in support of outgroup members may consist of attending protests, advocacy for outgroup members, dispelling myths about the outgroup, engaging an ingroup member in a discussion regarding oppression and the experiences of outgroup members, voting for gender equality initiatives, confronting ingroup members' discriminatory actions, and donating time and resources to outgroup causes (Evans, 2002; Jones et. al., 2014). For men allies of women in the workplace, action may involve displaying symbols in the workspace, advocating for changes in employment practices and policies, and speaking up against sexual harassment (Davis \& Wagner, 2005). The present study will explore the dimension of action through factor analysis. The dimension action is theoretically distinct from social support skills and instrumental support skills in that a man may have the ability to empathize with and listen to an women experiencing sexism at work, but unless he does something, he has not acted. Simply because individuals may possess a skill does not mean they have put it into action. 


\section{STUDY I. THE DEVELOPMENT AND INITIAL PSYCHOMETRIC EVALUATION OF THE M.A.W.W.}

Drawing upon models of allyhood development and related conceptual frameworks, we hypothesized the following:

H1) An exploratory factor analysis (EFA) of our initial item pool will find the intended six factors: distal awareness, proximal awareness, knowledge, social support, instrumental support, and action.

\section{Method}

The first step in the development of a scale is to clearly define what construct(s) the scale will measure (Devellis, 2003), as we have done with the concept of allyhood and our six predicted allyhood factors in the introduction to this study. The next task is to use these definitions to generate an item pool for subject matter experts (SMEs) to evaluate (Devellis, 2003; Kumar \& Kamalanabhan, 2014; Yi 2009). All items in the initial item pool should be well-grounded in substantive theory (Churchhill, 1979; Spector, 1992). Additionally, all items should have a similar level of specificity. Some scales in their application are global in their nature and some are more narrowly tailored, more specific (Clark \& Watson, 1995). For instance, a scale designed to assess a personality trait for universal application is global, while a scale used to measure the engagement level of third-shift workers in the healthcare industry is more narrow, requiring items related expressly to engagement, third shift workers, and the healthcare industry. If the scale is specific, the items need to match this level of specificity by setting narrow boundaries that help to confine the construct. If the scale purports to measure a 
global phenomenon, then the items need to have broad application (Clark \& Watston, 1995; Devellis, 2003).

The M.A.W.W. is specific in nature. It seeks to identify men allies only and focuses on men's relationship with women, all in the confines of the workplace. Consequently, the M.A.W.W. was administered to men only, exploring the relationship between the participant and women by surveying his attitudes toward and beliefs about women. Lastly, in keeping with an appropriate level of specificity, all items were related to the workplace.

The proposed measure used Likert-type scales to assess responses on all items. The Likert scale consists of a declarative statement followed by responses (Likert, 1932). The responses for the proposed measure were assessed on a 5-point, bimodal scale with a neutral midpoint. The response items were (1) strongly disagree, (2) disagree, (3) neither agree nor disagree, (4) agree, and (5) strongly agree. Likert-type scales are highly recommended for items that measure opinions, beliefs and attitudes (Devellis, 2003; Herbenick, 2007) as is the case with the M.A.W.W.

SME Review. The first step taken to validate the proposed scale was to develop a large item pool and have the item pool and response options reviewed by a group of SMEs (Kumar \& Kamalanabhan, 2014; Podsakoff, 2003). This review by SMEs provides content validity in support of the proposed measure (Kumar \& Kamalanabhan, 2014). The SME review for the proposed items in the M.A.W.W. was conducted in two stages. In the first stage, five SMEs were presented with 84 items. Four of these SMEs were women and one was a man. These initial SMEs were experts in the field of Gender 
Studies and associated with various universities throughout the United States. Two of these SMEs were also external consultants for private firms that service organizations.

At this stage of the M.A.W.W. validation, there were six dimensions of allyhood development that were hypothesized to be the basis of the proposed measure: 1.) distal awareness, 2.) proximal awareness, 3.) knowledge and skills, 4.) social support, 5.) instrumental support and 6.) action. Each of the 84 items submitted to the SMEs was preclassified in one of these six dimensions. SMEs rated how well they believed each item related to the dimension it purported to measure on a scale of 1 (poorly relates) to 5 (relates well). Additionally, the SMEs were encouraged to give any further insight they may have about each item, its clarity, and the scale in general, using open-ended response questions. See Appendix A for the full questionnaire).

The SME review process eliminated twenty-five items and prompted ten items to be rewritten to increase clarity and to strengthen the item's association with the proposed dimension. Some items were deleted because the items lent themselves to multiple interpretations. However, most of the items deleted were because they did not relate well to any of the pre-classified dimensions or they related to multiple dimensions. For instance, two of the SMEs thought that one item "Sometimes I wonder if I am paid more than my female coworkers who do the same job" could be considered linked to both proximal awareness and social support. Because of this ambiguity, this item was eliminated.

In the second stage of the SME review, two additional SMEs were presented with an online list of all M.A.W.W. items in random order, and asked to match every item to one of the six dimensions. In addition to the matching instructions, the two SMEs were 
given a brief description of each dimension. The SMEs were also provided ample space to make comments and offer any further insights. For this online exercise, the SME had to drag and drop the item into the dimension's box to associate a particular item with one of the six dimensions of allyhood development. See Appendix B for full questionnaire. No items were eliminated as a result of the matching exercise process, but four items were rewritten to increase clarity and strengthen the item's association with the proposed dimension. After processing the SME feedback from both exercises, twenty-four items were deleted and fourteen items were modified.

Exploratory Factor Analysis. Once the SME review process was completed, the list of 59 items were administered to 268 adult working men age 18 and older to conduct an exploratory factor analysis. Employment was defined as currently working 30 hours or more per week. The survey was developed with Qualtrics survey software and administered to participants through Amazon's Mechanical Turk. Amazon's Mechanical Turk (MTurk) data collection system is a widely used source for gathering information from online subjects (Cheung, Burns, Sinclair \& Silter, 2017). The system pre-qualifies participants so that only those who qualify for a survey are permitted to take it. The MTurk participants comprise a generally diverse population not only in terms of race, age and gender, but geography and industry as well (Litman, Robinson, \& Abberbock, 2017). MTurk participants were paid $\$ 2.61$ for their participation, and the average time to complete the survey was 14.29 minutes with the exclusion of three outlier submissions that recorded a completion time of over 40 minutes. Furthermore, MTurk has proven to procure internally and externally valid data that meet Shadish, Cook, and Campbell's (2002) statistical conclusion and construct validity standards (Cheung et al., 2017). 
The 59 items utilized for the exploratory factor analysis included the observations of 268 subjects and achieved a power level of .80 using G Power 3.1. A power analysis consists of four variables: number of subjects, effect size, alpha, and power (Cohen, 1988). The effect size is the strength of the result found, the alpha indicates to what degree the effect size is generalizable to a population and the power represents the probability of finding true significance (Cohen, 1988). It is generally recommended for scale validation that a small to medium effect size of approximately .15 (Devellis, 2003; Nunnaly, 1978), an alpha of .05 (Cohen, 1988), and a minimum power of .80 (Cohen, 1988) be used to determine the number of subjects. With 268 observations, the exploratory factor analysis yielded a power analysis of .80, meeting Cohen's (1988) recommended standard.

An exploratory factor analysis is a statistical technique that groups items of a scale into a reduced sets of factors that represent a summary of those items (Gorsuch, 1983; Hair, Anderson, Tatham, \& Black, 1995; Tabachnick \& Fidell, 2007). The grouping allows for a more meaningful understanding of the phenomena's theoretical structure. Grouping, or factorization, generally occurs because all the items of a scale are associated with one latent variable and, by extension, these items will likely generate similar responses from participants who are administered a scale that contains these items (Williams, Brown, \& Onsman, 2010). To indicate how the scale's items should be factored, an exploratory factor analysis yields correlation coefficients between the items and the factors. The correlation coefficient is known as a factor loading, and those items that tend to have similar factor loadings are assembled together under a common factor. The process yields an initial solution that contains the maximum number of acceptable 
factors. To further examine this initial solution, the factor loadings are "rotated" to shed further evidence on what will be the final solution (Williams et al., 2010).

Rotation is a method of emphasizing the highest loadings and deemphasizing the lowest loadings so that the simplest structure possible can emerge in the factor analysis (Thompson, 2004). There are two types of rotation: orthogonal and oblique. Orthogonal rotation refers to an assumption that the factors are independent (i.e., not correlated with one another). Oblique rotation, by comparison, is the technique generally used when theory dictates that the factors are correlated. Orthogonal rotations consist of varimax, quartamax and equamax. Oblique rotation consists of oblim, promax and direct quartimin (Thompson, 2004).

Best Factor Solution. Beginning with the maximum number of factors indicated by the initial solution, each factor scenario is reviewed to determine whether it offers the best interpretation of the data (Williams et al., 2010). Factor solutions that have less than three items, or are primarily made up of items with factor loadings of less than .30, are to be removed from consideration (Gorsuch, 1983). For instance, if the initial solution is a five factor solution, then the five factor solution is reviewed to see if it is the best interpretation of the data. Then a forced four factor solution is reviewed; next a forced three factor solution is reviewed, followed by a forced two factor solution. Once the best factor solution is decided upon, the exploratory factor analysis moves into the item retention phase.

For item retention, Khan (2006) recommends a two prong approach. The first prong of item retention is a purely data-driven method that eliminates items from the scale that have factor loadings less than .40 . The second prong is a theoretical approach 
that eliminates items on the basis of conceptual redundancy. Once the scale length is optimized through this process the scale is then ready for a confirmatory factor analysis.

Exploratory Factor Results. Using SPSS Statistics 20.0 and the data from the 268 observations of the 59 items, an exploratory factor analysis was conducted and, in this case, principal axis factoring was used (Worthington \& Whittaker (2006). With a Kaiser-Meyer-Olkin value greater than .90 (.927; Tabchnick \& Fidell, 2001) and a statistical significance on Bartlett's test of sphericity: $\chi^{2}=10110.64, p<.000$, initial results indicated that the M.A.W.W. in its 59 item form was appropriate for factor analysis.

To determine the number of factors in the initial solution, two common approaches were used: 1) the Scree Plot approach and 2) the Kaiser-Guttman Rule method (Gorsuch, 1990; Kim \& Mueller, 1978). The scree plot approach follows the notion that there are the same number of factors as there are items in the scale. Using a two dimensional graph, the factors generated from the analysis are plotted on the $\mathrm{x}$-axis and the eigenvalues of the factors are plotted on the y-axis. The eigenvalues are scores that when totaled equal the number of items in the measure (Kim \& Mueller, 1978). Eigenvalues also represent the variance accounted for by each underlying factor (Preacher \& MacCollum, 2003). For instance, in a scale with twenty items, an eigenvalue of 10 for Factor 1 would represent a variance of 50\%. If Factor 2 had an eigenvalue of 5, then Factor 2 would represent a variance of $25 \%$.

The ideal pattern for a scree plot is a steep curve, followed by a bend or the "elbow," which then flattens out into a line. The flattened line is thought of as scree, a concept that stems from the rubble that is often found at the base of a mountainside (Kim 
\& Mueller, 1978). Statistically speaking, the scree is error variation (Tabachnick \&

Fidell, 2000). The factors to retain are the factors on the steep curve and the elbow, and the factors to discard are the ones that form the scree (Kim \& Mueller, 1978). Figure 1 shows the scree plot for the 59 item M.A.W.W. 
Figure 1.

Scree Plot for the M.A.W.W.

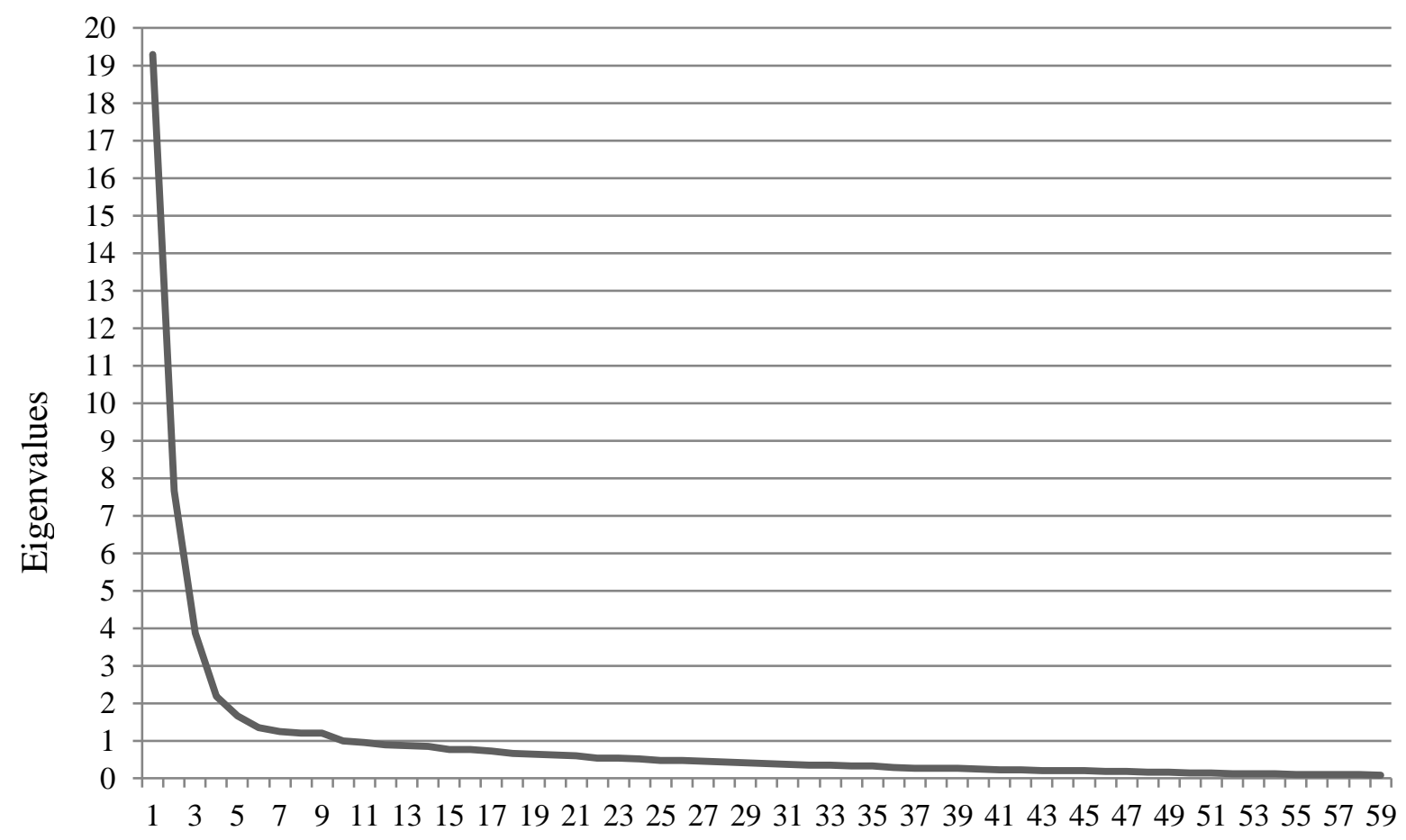

Factors

As shown in Figure 1, there are 59 potential factors, one for each item in the M.A.W.W. The first factor has an eigenvalue of 19.29 and the second factor has an eigenvalue of 7.67. In Figure 1 it appears that factor nine is the last point in the elbow and factor ten is the first point in the scree.

The Kaiser-Guttman Rule method is similar to the Scree Plot approach in that it also involves the use of eigenvalues. In the Kaiser-Guttman method, factors with eigenvalues of one or greater are retained, and factors with eigenvalues less than one are discarded (Kim \& Mueller, 1978). Under the Kaiser-Guttman Rule the first nine factors all have eigenvalues greater than one. Based upon the evidence generated by the scree 
plot approach and the Kaiser-Guttman Rule method, the M.A.W.W. was narrowed down from 59 factors to nine factors for this stage of the exploratory factor analysis.

Once an initial solution was achieved, the next step was to rotate the factor loadings in order to obtain an improved interpretation of the data. Because it was theorized that Distal Awareness, Proximal Awareness, Knowledge, Social Support, Instrumental Support, and Action would correlate with each other, an oblique rotation was used, and upon the recommendation of Osborne and Costello (2009) the promax form of oblique rotation was utilized. Multiple factor solutions were considered, beginning with the nine factor initial solution. Factor solutions four, five, six, seven, eight, and nine consisted primarily of item loadings of less than .30 and, in some cases, there were factors with only one or two items. Factor solutions one and two eliminated too many items and rendered the M.A.W.W. conceptually meaningless, a consideration to heed as suggested by Gorsuch (1983) and Williams, Onsman, and Brown (2010). The three factor solution offered the best interpretation. In the three factor solutions, all items had factor loadings greater than or equal to .30 , and each factor contained three or more items.

Eventually, the three factors were labeled "Knowledge \& Awareness," "Action," and "Skills \& Capacity." The Knowledge \& Awareness factor accounted for $32.67 \%$ of the variance in the data, the Action factor accounted for $13.00 \%$ of the variance, and the Skills \& Capacity factor accounted for $6.57 \%$ of the variance. In total, these three factors explained $52.24 \%$ of the total variance in the data, exceeding the recommended standard of 50\% (Williams et al., 2010). As a results, the six factor hypothesis (H1) was not supported. 
Regarding item retention for the M.A.W.W., the 59 items were reviewed as suggested by Kahn (2006)'s two prong approach. There were 37 items that did not have factor loadings of .40 or greater so those items were eliminated. Furthermore, five items were then eliminated because they were conceptually redundant. For example, the item "It is more difficult for women to advance in the workplace as compared to men" was eliminated from the M.A.W.W. because it was redundant when compared to "When a woman is pregnant, her workplace must provide her with necessary accommodations to perform her job." Both items seemed to detect the participants' knowledge of legal mandates. Also, these two items had a strong correlation $(r=.73)$, suggesting that they both are associated with the same construct. Likewise, the item "Compared to women, I recognize that some benefits at work come more easily to men" was eliminated from the M.A.W.W. as it was deemed redundant with the item "It is easier for a man to get to the top of an organization than it is for a woman because of sexism." Both items explore participants' belief as to whether differing outcomes at work can be due to one's sex, however, the latter item captures this belief more directly and so was retained. These two items also had a very strong correlation $(r=.75)$. Factor loadings and cross loadings for the remaining seventeen items are reported in Table 1, and the factor intercorrelations are reported in Table 2. 
Table 1.

Exploratory Factor Analysis Factor Loadings

Item content by factor

26. I am familiar with a number of laws that give women protection from unequal treatment

17. When a woman is pregnant, her workplace must provide her with necessary accommodations to perform her job.

19. It is more difficult for women to advance in the workplace as compared to men.

1. It is easier for a man to get to the top of an organization than it is for a woman because of sexism.

18. Over the years I have learned how to point out places for women to research about their rights at work.

31. I am familiar with studies that show women are penalized for being assertive at work in ways that men are not.

$\begin{array}{llllll}7 . & \text { Compared to women, I recognize that some benefits at work come } & & \mathbf{7 4} & .12 & .22\end{array}$ more easily to men.

2. I think women face barriers in the workplace that I do not.

42. I engage in conversations with others regarding the importance of women's equality at work.

16. I steer clear of discussions regarding the inequality of women at work. (REVERSE)

39. If I see discrimination against a woman at work, I speak up against it.

30. At work, I wouldn't get into as much trouble if I talked down to a woman than if I had talked down to another man.

6. I am a member of a group that promotes women's workplace rights. $\quad \begin{array}{llll}.33 & \mathbf{4 5} & -.36\end{array}$

59. I know about studies that show women at work are more likely to be $\quad \begin{array}{llll}- & .17 & \mathbf{. 6 1}\end{array}$ interrupted while speaking than men are.

.05

22. If asked, I can direct a woman who may have a problem to the key $\quad \begin{array}{lll}.13 & .22 & \mathbf{5 6}\end{array}$ people at work who may be of help.

40. I can listen to women's workplace concerns in a nonjudgmental way. $\quad \begin{array}{lll}12 & .19 & \mathbf{. 4 9}\end{array}$

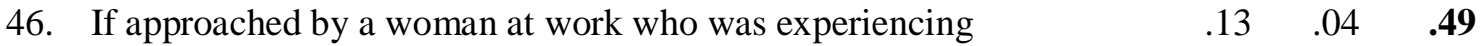
discrimination, I have the skills to be able to talk with her about it.

Note. Bold numbers indicate which factor each item loaded onto. 1= Knowledge \& Awareness, $2=$ Action, and $3=$ Skills \& Capacity.

Table 2.

Factor intercorrelations

\begin{tabular}{lccc}
\hline \multicolumn{1}{c}{ Factor } & Knowledge \& Awareness & Action & Skills \& Capacity \\
\hline Knowledge \& Awareness & 1.00 & .35 & .34 \\
Action & .35 & 1.00 & .18 \\
Skills \& Capacity & .34 & .18 & 1.00 \\
\hline
\end{tabular}




\section{Reliability}

The utility of a scale depends greatly upon its reliability. The reliability of a scale refers to the scale's ability to produce scores that are consistent and repeatable (Schmitt, 1996; Streiner, 2003). If a scale generates different scores through repeated administrations under similar circumstances, then the scale is not reliable and is not a psychometrically sound instrument. In general, there are two types of reliability used in the validation of scales: external and internal (Shadish et al., 2002). External reliability refers to the extent to which a scale or assessment varies over time, from one use after another. Test-retest and inter-rater agreement are frequently used techniques to measure the scale or assessment's stability over time (McLeod, 2007). Internal reliability is a determination as to whether the measure is consistent within itself or not as might be demonstrated with a split half reliability test or internal consistency analysis (McLeod, 2007).

Test-retest is one example of external reliability to validate a scale (Shadish et al., 2002). For test-retest reliability, a scale is administered over multiple time points (T1, T2), with a relatively short period of time between administrations. The longer the period of time between scale administrations, the greater the chance that threats to the scale's reliability may arise because of the lapse in time. Internal consistency is an example of internal reliability and is the recommended form of reliability for scales that measure attitudes, opinions and beliefs such as the M.A.W.W. (Schmitt, 1996). Internal consistency reliability of a scale is determined by correlations between different items of the same scale and in essence internal consistency represents whether a random selection of items of the scale that propose to measure the same construct produce similar scores. 
Internal consistency reliability is represented by Cronbach's Alpha, a statistic calculated from a pairwise correlation between the scale's items (Cronbach, 1951).

With regard to the seventeen item version of the M.A.W.W., the internal consistency reliability for the Knowledge \& Awareness factor was .91 $(n=8$, interitem correlation range of $.58-.78)$, for the Action factor it was $.81(n=5$, interitem correlation range of .37 - .78), and for the Skills \& Capacity factor it was .73 $(n=4$, interitem correlation range of .36 - .45). The overall internal consistency reliability for all seventeen M.A.W.W. items was .85. All of these reliability values fell into the acceptable to excellent range (Cohen, 1992). See Appendix C for the entire listing of descriptive statistics and Appendix D for interitem correlations for each factor.

\section{V.STUDY II. CONFIRMATON OF THE M.A.W.W.}

Once a scale has been evaluated with an EFA, the remaining items and their link to the proposed factors need to be confirmed (Byrne, 2010). EFA and CFA are similar approaches in validating a scale, but in EFA the data are merely explored whereas in CFA the number of factors are specified in advance and the process confirms or rejects whether the data fit the proposed model (Byrne, 2010). Additionally, the validation of a scale requires an internal consistency overall score that is greater than .70 at a minimum (Cohen, 1992). For our CFA analysis of the M.A.W.W., we predicted the following:

H1) A confirmatory factor analysis (CFA) will reproduce evidence for the existence of three factors: Knowledge \& Awareness, Action, and Skills \& Capacity.

H2) The M.A.W.W. will yield an internal consistency reliability overall score that falls in the acceptable to excellent range. 


\section{Participants}

The list of seventeen items generated by the EFA in Study I were next administered to 195 employed adult men to conduct a confirmatory factor analysis (CFA). Employment was defined as working 30 hours or more per week, and the survey was only administered to men 18 years of age or older. As with the exploratory factor analysis survey, the survey to test the CFA was again administered on Amazon's Mechanical Turk, and participants were paid $\$ 1.92$ for their completion of the survey. Data from three subjects were eliminated as a result of the failure of various manipulation checks. For instance, when the question explicitly told participants to select the response "agree," participants who failed the manipulation check instead selected another response option. There were three such checks. The first attention check was placed midway in the M.A.W.W. The second and third checks were placed in the convergent/divergent validity scales that accompanied the administration of the M.A.W.W.

Participants in the final sample $(N=194)$ ranged in age from $18-75$, with the mean age range being 26-35 years of age. With regards to race, the participants reported being White/Caucasian (77.32\%), Hispanic/Latino (8.25\%), Asian (5.67\%), Black/African American (5.15\%), other race (2.06\%), Indigenous American/Alaskan Native (1.03\%), and Pacific Islander or Native Hawaiian (.52\%). Ninety-one and twentyfour hundredths percent (91.24\%) stated that they were Heterosexual/Straight, $4.64 \%$ as Homosexual/Gay, and 4.12\% reported being Bisexual. On a scale of 1-8 where 1 represented a political affiliation of "extremely liberal" and 8 represented "extremely conservative," the mean was exactly in the middle $(M=4.5, S D=2.45)$. As far as highest level of education, a Bachelor's Degree was the most commonly reported (45.88\%), 
followed by Some College, No Degree (20.10\%), Associate Degree (12.37\%), Master's Degree (11.34\%), High School Diploma (8.76\%), Professional Degree (1.03\%), and Doctorate (.52\%). Forty-eight and forty-five hundredths percent (48.45\%) of the sample self-identified as managers, and $51.55 \%$ were non-managers at their current place of employment. About thirty-seven percent of the participants reported being at their current places of employment for 3-5 years (37.11\%), followed by $29.90 \%$ for 5-10 years, $14.43 \%$ for $11-12$ years, $13.92 \%$ less than 2 years, and $4.64 \%$ were at their jobs for 21 years or more.

\section{Procedures}

Survey administration and data collection took place through Amazon's Mechanical Turk Survey System, and mirrored those described in Study 1. Following Hau and Marsh's (2004) recommendation that, to conduct a sound CFA, a scale should be administered to a sample that meets the ratio of ten participants per item, the seventeen item M.A.W.W. was administered to 196 participants. Having gathered acceptable data from 194 participants, the M.A.W.W. exceeded minimum standards (Hau \& Maxwell, 2004; MacCallum, Browne, \& Sugawara, 1996; Quintana \& Maxwell, 1999).

\section{Confirmatory Factor Analysis}

Confirmatory factor analysis is a statistical procedure that uses a specific factor structure that confirms which items are associated with factors. The CFA indicates how well the proposed structured factor model fits the data that is collected when a scale is administered. The proposed structured factor model is created either derived from theory, an EFA, or a combination of both (Byrne, 2010). Similar to an EFA, a CFA results in loading factors that describe the strength or weakness of the relationship between a factor 
and an item (Thompson, 2004). More specifically, the factor loadings represent the causal effect of a factor on an item. Factor loadings differ from one another mainly because the factor exerts varying degrees of influence on one item versus another item (Thompson, 2004).

When conducting a CFA, the data must be analyzed first for distribution normalness. Distribution normalness is examined by evaluating each item's skewness and kurtosis (Williams et al., 2010). Skewness of less than .1 and kurtosis of less than 3.0 are acceptable outcomes (Byrne, 2010). If skewness or kurtosis occurs, then the researcher must examine the data to see if outliers exists and if their removal from the dataset would bring skewness and kurtosis into acceptable ranges without a significant impact on the goodness-of-fit indexes (Byrne, 2010).

Goodness-of- fit indexes are measure that describe how well or poorly the proposed facture structure model fits the data. The main indicators of goodness of fit are: a Root Mean Square Error Approximation (RMSEA) <.08, Standardized Root Mean Residual $($ SRMR) <.1, Comparative Fit Index $(\mathrm{CFI})<.90$, Tucker Lewis Index (TLI) $<.90$, as well as a statistically significant Chi Square Test $\left(\chi^{2}\right)(\mathrm{Hu} \&$ Benter, 1995; Martens, 2005; Weston \& Gore, 2006).

\section{Confirmatory Factor Analysis Results}

On the basis of the EFA, the M.A.W.W. was divided into three factors (or subscales): Knowledge \& Awareness, Action, and Skills \& Capacity. R Programming (Yves, 2012) was used to conduct a CFA of the seventeen EFA items with the data from the 192 participants. The seventeen items used in the CFA were a subgroup of the 59 items used in Study I and no item text was changed. Additionally, several other scales 
were administered where their results would later be used to assess the validity of the M.A.W.W. Upon an initial investigation, the data slightly missed acceptable statistical levels with suboptimal absolute fit results of RMSEA $=.13$ and SRMR $=.1$. Further investigation revealed that two items had poor loading factors. Item 18 "Over the years I have learned how to point out places for women to research about their rights at work," which received a loading factor of .26, and Item 30 "At work, I wouldn't get into as much trouble if I talked down to a woman than if I had talked down to another man," which received a factor loading result of .02 , were both omitted from the analysis. A CFA was conducted again with the remaining fifteen items. These remaining fifteen items met all recommended statistical standards of a CFA and constitute the final version of the M.A.W.W.

Firstly, the fifteen items of the final M.A.W.W. met the standards for distribution normality as outlined by Weston and Gore (2006) where acceptable levels of skewness and kurtosis are $<.80$ and $<3.0$ respectively. Table 3 shows the skewness and kurtosis for each of the fifteen items. 
Table 3.

Skewness and Kurtosis of Fifteen Items in the Final M.A.W.W.

Item Content by Factor
Skewness Kurtosis

\begin{tabular}{ll}
-.38 & 2.35 \\
-.72 & 2.57 \\
-.47 & 2.06 \\
-.33 & 2.21 \\
-.11 & 1.90 \\
-.60 & 2.58 \\
-.50 & 2.42 \\
-.20 & 2.30 \\
-.07 & 2.19 \\
-.45 & 3.03 \\
-.27 & 2.33 \\
.03 & 2.33 \\
-.26 & 2.34 \\
-.51 & 2.45 \\
-.11 & 2.18 \\
\hline
\end{tabular}

26. I am familiar with a number of laws that give women protection from unequal treatment

17. When a woman is pregnant, her workplace must provide her with necessary accommodations to perform her job.

19. It is more difficult for women to advance in the workplace as compared to men.

1. It is easier for a man to get to the top of an organization than it is for a woman because of sexism.

31. I am familiar with studies that show women are penalized for bein assertive at work in ways that men are not.

2. I think women face barriers in the workplace that I do not.

7. Compared to women, I recognize that some benefits at work come more easily to men.

42. I engage in conversations with others regarding the importance of women's equality at work.

16. I steer clear of discussions regarding the inequality of women at work. (REVERSE)

39. If I see discrimination against a woman at work, I speak up against it.

6. I am a member of a group that promotes women's workplace rights.

59. I know about studies that show women at work are more likely to be interrupted while speaking than men are.

22. If asked, I can direct a woman who may have a problem to the key people at work who may be of help.

40. I can listen to women's workplace concerns in a nonjudgmental way.

46. If approached by a woman at work who was experiencing
discrimination, I have the skills to be able to talk with her about it.

Note. Acceptable ranges for skewness are <.8 and for kurtosis <3.0 (Wetson \& Gore, 2006).

To determine whether the data of the final version of the M.A.W.W. fit the

proposed model, both absolute and incremental fit indexes were used (Hu \& Benter,

1995; Martens, 2005; Weston \& Gore, 2006). The absolute model fit was evaluated with

RMSEA, the root mean-square error approximation, and SRMR, the standardized root-

mean residual. The results showed an RMSEA of .07 which met the acceptable standard

of $<.08$ and an SRMR of .06 which met the acceptable standard of <.1 (Weston \& Gore, 
2006). The incremental model fit was examined with the CFI, comparative fit index and the TLI, Tucker Lewis Index. The results showed a CFI of .94 which met the acceptable standard of $>.90$ and a TLI of .93 which met the acceptable standard of $>.90$ (Weston \& Gore, 2006). In summary, the CFA provided a good fit to the data: $\chi^{2}=174.27, \mathrm{df}=87$, $p<.001, \mathrm{RMSEA}=.07,90 \% \mathrm{CI}[.06, .09], \mathrm{SRMR}=.06, \mathrm{CFI}=.94$ and TLI $=.03$. All items loaded significantly onto their intended factors. The loadings for Knowledge \& Awareness ranged from .67 to 1.0. For Action the factor loadings ranged from .35 to .86 , and for Skills \& Capacity the factor loadings ranged from .74 to .90. Factor loadings and factor intercorrelations are presented in Tables 4 and 5, respectively, and a path diagram for the final version of the M.A.W.W. is presented in Figure 2. Furthermore, the results showed that Hypothesis (H1) was not supported. 
Table 4

Confirmatory Factor Analysis Loadings for M.A.W.W. Items

$\begin{array}{llllc}\text { Item Content by Factor } & \text { B } & \text { SE } & Z & \begin{array}{c}p \\ \text { value }\end{array}\end{array}$ Beta

\section{Knowledge and Awareness}

19. It is more difficult for women to advance in the workplace as compared to men.

31. I am familiar with studies that show women are penalized for being assertive at work in ways that men are not.

7. Compared to women, I recognize that some benefits at work come more easily to men.

1. It is easier for a man to get to the top of an organization than it is for a woman because of sexism.

$\begin{array}{llllllll}\text { 2. I think women face barriers in the workplace that I do } & & .93 & .06 & 14.51 & 0 & & .85\end{array}$ not.

17. When a woman is pregnant, her workplace must provide $\quad \begin{array}{llllll}.72 & .07 & 10.10 & 0 & & .66\end{array}$ her with necessary accommodations to perform her job.

$\begin{array}{llllllll}\text { 26. I am familiar with a number of laws that give women } & .67 & .08 & 8.84 & 0 & .60\end{array}$ protection from unequal treatment at work.

\section{Action}

$\begin{array}{lllllll}\text { 16. I steer clear of discussions regarding the inequality of } & & .87 & .08 & 10.92 & 0 & .75\end{array}$ women at work. (REVERSE)

42. I engage in conversations with others regarding the $\quad \begin{array}{llllll} & .85 & .07 & 11.63 & 0 & .79\end{array}$ importance of women's equality at work.

$\begin{array}{lllllllll}\text { 6. I am a member of a group that promotes women's } & & .56 & .09 & 6.57 & 0 & .49\end{array}$ workplace rights.

$\begin{array}{lllllll}39 . & \text { If I see discrimination against a woman at work, I speak } & .45 & .07 & 4.93 & 0 & .38\end{array}$ up against it.

\section{$\underline{\text { Skills \& Capacity }}$}

40. I can listen to women's workplace concerns in a nonjudgmental way.

46. If approached by a woman at work who was experiencing discrimination, I have the skills to be able to talk with her about it.

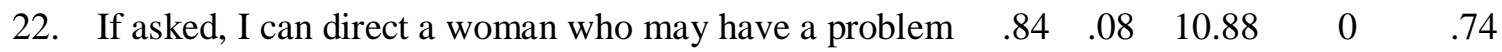
to the key people at work who may be of help.

$\begin{array}{lllllll}\text { 59. I know about studies that show women at work are more } & .74 & .08 & 9.43 & 0 & & .66\end{array}$ likely to be interrupted while speaking than men are.

Note. $\mathrm{B}=$ factor loading, $\mathrm{SE}=$ standard error, $\mathrm{Z}=\mathrm{z}$ value, and Beta $=$ standardized regression coefficients. 
Table 5.

Factor Intercorrelations.

Factors Knowledge \& Awareness Action Skills \& Capacity

$\begin{array}{llll}\text { Knowledge \& Awareness } & 1.00 & .73 & .66\end{array}$

$\begin{array}{llll}\text { Action } & .73 & 1.00 & .56\end{array}$

Skills \& Capacity

$.66 \quad .56 \quad 1.00$ 
Figure 2 .

Path Diagram for the fifteen item, final version of the M.A.W.W, showing 1.) correlations between factors and 2.) the factor loadings of factor on items.

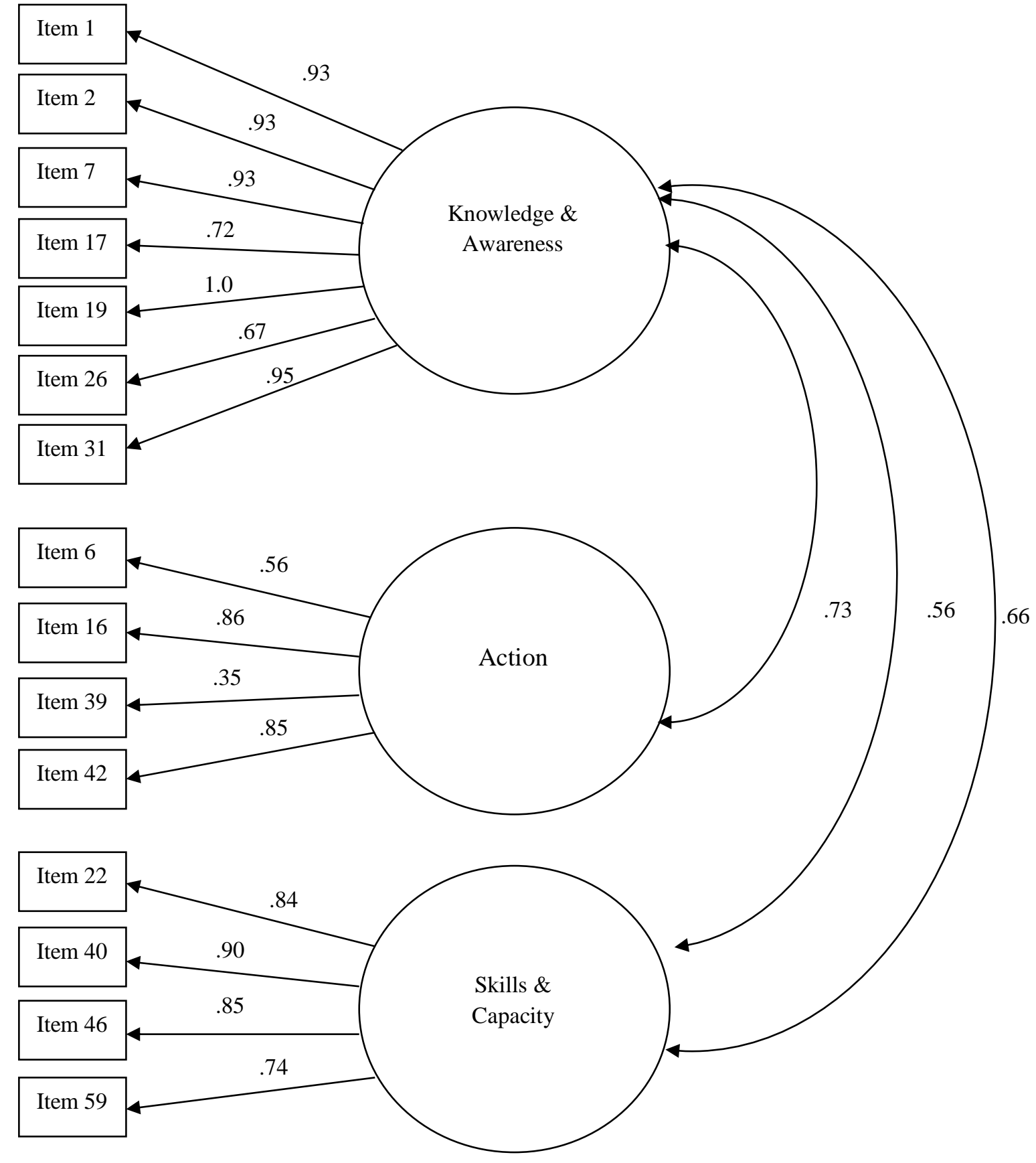




\section{Reliablity}

With regards to the 15-item M.A.W.W., the internal consistency reliability for the factor Knowledge \& Awareness was .91 ( $n=7$, interitem correlation range of .63 - .78), for the factor Action it was $.74(n=4$, interitem correlation range of $.28-.80)$, and for the factor Skills \& Capacity it was $.73(n=4$, interitem correlation range of $.40-.45)$. The 15-items in the M.A.W.W. had an overall internal consistency reliability of .87. These reliability values for the three factors and for the overall M.A.W.W. fell into the acceptable to excellent range, supporting Hypothesis $(\mathrm{H} 2)$. See Appendix E for the entire listing of descriptive statistics and Appendix F for the interitem correlations for each factor.

\section{STUDY III. ASSESSMENT OF THE VALIDITY OF THE M.A.W.W.}

Validity refers to a scale's ability to measure what it claims it measures. In a broad sense, there are three types of validity: construct, content, and criterion (Rominger \& Sandoval, 1998). Construct validity is the extent to which a scale measures the theoretical concepts that it purports to measure (Ployhart \& Holtz, 2008). Because the M.A.W.W. purports to measure men's allyhood toward women at work, construct validity consists of evidence that the M.A.W.W. does in fact measure men's allyhood. Content validity is established when a scale's items cover all the aspects of the construct being measured, and criterion validity involves the degree to which a scale can predict specific outcome variables (Ployhart \& Holtz, 2008). To validate a scale, construct validity is what is generally required (Furr \& Bacharach, 2008; Struwig, Struwig, \& Stead, 2001). 


\section{Construct Validity}

Construct validity is generally shown through evidence of two subtypes: convergent and divergent validity (Domino \& Domino, 2006; John \& Benet-Martinez, 2000; Struwig et al., 2001). Convergent validity is demonstrated when the constructs of two different scales that are theoretically thought to be similar are, in fact, observed to be similar. Divergent validity is demonstrated when the constructs of two different scales that are theoretically believed to be dissimilar are dissimilar in actuality (Domino \& Domino, 2006). The strength of the similarity or dissimilarity is represented by a correlation coefficient $(r)$ where .10 represents a small effect size, .30 represents a moderate effect size, and .50 represents a large effect size (Cohen, 1992). Evidence of convergent validity between two different scales will yield a positive correlation coefficient, and evidence of divergent validity will yield a negative correlation coefficient (Jones et al., 2014). Furthermore, when two different scales are theorized to be unrelated, evidence of validity is shown if there is no correlation between the two scales (Jones et al., 2014).

An example of convergent validity would be the correlational comparison between the Neosexism Scale (Tougas, Brown, Beaton, \& Jolly, 1995) and the Attitudes toward Homosexuals Scale (Bem, 1993) as discussed in Bem (1993). Theorizing that negative attitudes toward homosexuals are often determined by rigid views of gender roles, The Attitudes toward Homosexuals Scale was predicted to hold a positive correlation with the Neosexism Scale, a scale which itself measures a person's negative and prejudicial views toward women. Statistical analysis showed the Neosexism Scale 
has a moderate to strong positive correlation with the Attitudes toward Homosexuals Scale, thus establishing convergent validity (Bem, 1993).

There are several instruments commonly used in research that assess affirming attitudes toward women. The Attitudes toward Women Scale (AWS) (Spence, Helmreich, \& Stopp, 1973) is a commonly used instrument that assesses the participant's views regarding women's rights and privileges in society. The Humanitarian Egalitarian Scale (Katz \& Haas, 1988) is another scale that assessing affirming attitudes toward women. Although similar to the AWS, the Humanitarian Egalitarian Scale focuses primarily on women's roles in society.

Additionally, there are several instruments commonly used in research that assess negative and prejudicial attitudes toward women. Three such scales are the Neosexism Scale (Tougas et al., 1995), the Social Dominance Orientation Scale (SDO) (Pratto, Sidanius, Stallworth, \& Malle, 1994), and the Ambivalent Sexism Inventory (ASI) (Glick \& Fiske, 1996), The Neosexism Scale assesses the participant's views against the backdrop of public policies (Tougas et al., 1995), and the ASI assesses the participant's attitudes toward women with items that reflect hostile and benevolent sexism (Glick \& Fiske, 1996). The SDO is slightly different than these two scales in that it does not measure attitudes toward women directly, but instead measures the participant's opinions and attitudes with regard to intergroup relations and the support for the existence of a hierarchal group structure (Pratto et al, 1994).

Personality scales are also used to demonstrate validity in scales related to gender, but their purpose is primarily to show that there is no correlation between the personality extroversion and gender beliefs, as theory suggests that there is no relationship between 
the two. (Jones, 2014.) The NEO Personality Inventory 3 (NEO PI-3) (Costa \& McCrae, 1992) is a personality scale that is commonly used in scale research that includes an extraversion factor (Jones, 2014).

\section{Hypothesis}

H1) The M.A.W.W. will correlate positively with scales assessing affirming attitudes toward women in general, including the AWS (Spence, Helmreich, \& Stopp, 1973) and the Humanitarian Egalitarian Scale (Katz \& Haas, 1988), (H1a), correlate negatively with scales assessing negative and prejudicial attitudes against women, including the Neosexism scale (Tougas et al., 1995), the SDO (Pratto et al., 1994), and the ASI (Glick \& Fiske, 1996), (H1b), and have no correlation with the personality trait extroversion, as measured by the NEO PI-3 (Costa \& McCrae, 1992) (H1c).

\section{Method}

When the M.A.W.W. was administered in the 37 item version in Study I and the seventeen item version in Study II, other scales were administered in succession on both occasions. The 17 items administered in Study II were a subgroup of the 24 items administered in Study I, and no item text was changed when the M.A.W.W. was shortened. As a result, responses to the 15 items of the final M.A.W.W. were extracted from Study I, which was used for the EFA and then used to assess the validity of M.A.W.W. by exploring potential correlations with other scales simultaneously administered. Similarly, the responses to the 15 items of the final M.A.W.W. were extracted from the CFA and used to assess the validity of the M.A.W.W. by exploring potential correlations with the scales that were administered in that setting. The scales 
other than the M.A.W.W. that were administered in Studies I and II were varied in that some scales were theorized to positively correlate with the M.A.W.W., some were hypothesized to negatively correlate with the M.A.W.W., and a personality assessment was administered under the hypothesis following prior studies that there would be no correlation with the M.A.W.W. (e.g., Jones et al., 2014).

\section{Instruments}

Men's Allyhood toward Women in the Workplace. As shown in Study II, the final version of the M.A.W.W. consists of fifteen items, originating with 84 items pared down to 59 through the SME review, then pared down to seventeen through the EFA, and finally to fifteen items after the CFA suggested the additional elimination of two more items. The final version of the M.A.W.W. has three subscales: Knowledge \& Awareness, Action, and Skills \& Capacity. The internal consistency reliability for the full scale has a rating of good, nearly excellent $(\alpha=.87)$ with reliability of the subscales Knowledge $\&$ Awareness $(\alpha=.91)$, Action $(\alpha=.74)$, and Skills \& Capacity $(\alpha=.73)$ falling in the range of acceptable to excellent.

Attitudes toward Women Scale. The Attitudes towards Women Scale (AWS; Spence, Helmreich, \& Stopp, 1973) is a 25-item instrument that is the most commonly used instrument for gender equality studies in the United States (Bailey \& Less, 1992). It is designed to assess attitudes towards "the rights, roles, and privileges women ought to have" (Spence et al, 1973, p. 39). Each item has four response options, where the lower value of disagree strongly represents more traditional attitudes and the higher value of agree strongly represents more liberal, pro-feminist views. The internal consistency reliability for the AWS is fairly similar for women and men participants, and has an 
overall reliability of $\alpha=.83$ (King, Phillips, Walker, \& O’Toole, 2014). Sample items include "It is insulting to women to have the "obey" clause remain in the marriage service", and "Women should assume their rightful place in business and all the professions along with men."

Neosexism Scale. The Neosexism Scale (Tougas, Brown, Beaton, \& Jolly, 1995) was designed to predict support for the feminist movement and attitudes toward women in general by primarily focusing on public policies. These public policies rest on the notion that opposition to progressive social policies provides the neosexist with a socially acceptable means of opposing women's aspirations (Tougas et al., 1995). High scores predict individuals who are less likely to support gender equality and affirmative action as a remedy. The Neosexism Scale contains eleven items with a seven point response range from strongly disagree to strongly agree, and the scale has a good internal consistency reliability ( $\alpha=.76$, Tougas et al., 1995).

Sample items include "Discrimination against women in the labor force is no longer a problem" and "Over the past few years, women have gotten more from government than they deserve."

Social Dominance Scale. The SDO scale (Pratto, Sidanius, Stallworth, \& Malle, 1994) was developed to examine respondent's preference for intergroup relations that are structured according to dominant versus inferior characterizations (Pratto et al., 1994). The SDO presents seven items that are tolerant of inequality and seven items that are proequality for a total of fourteen items. Respondents rate each item on a seven point scale regarding an attitudinal orientation from very negative to very positive. The seven proequality items are scored in reverse. The SDO has been shown to have good internal 
consistency reliability $(\alpha=.85)$ and has demonstrated moderate convergent validity with a positive correlation with antigay and lesbian attitudes (Pratto et al, 1994; Whiley \& Aegisdottir, 2000). Sample items include "Some groups of people are simply not the equals of others" and "If people were treated more equally we would have fewer problems in this country."

Humanitarian Egalitarian Scale. The Humanitarian Egalitarian Scale (Katz \& Haas, 1988) measures adherence to democratic ideals such as equality, social justice, and concern for others' well-being (Katz \& Haas, 1988). The scale consists of twenty-one items, assessed on five point scales ranging from strongly disagree to strongly agree, and has shown strong internal consistency reliability $(\alpha=.87)$ (Katz \& Haas, 1988; McConahay, 1986; Sears, 1988).

Ambivalent Sexism Inventory. The ASI (Glick \& Fiske, 1996) is a twenty-two item scale where eleven items assess a hostile view of gender relations and eleven items measure the participant's level of benevolent sexism. Hostile sexism refers to the idea that women are seen as seeking to control men. Benevolent sexism entails the perpetrator's characterization of women as persons in need of protection, support and adoration, but at the same time implying that women are weak and best suited for traditional gender roles such as child rearing (Glick \& Fiske, 1996). Benevolent sexism, in other words, restricts women by placing them on a pedestal (Glick \& Fiske, 1996). Participants respond to items in this measure using a six point scale that ranges from disagree strongly to agree strongly. The Ambivalence towards Men Inventory has demonstrated a strong internal consistency reliability $(\alpha=.87)$ (Glick \& Fiske, 1996). Sample items include "Once a woman gets a man to commit to her, she usually puts him 
on a tight leash" and "Women, as compared to men, tend to have a more refined sense of culture and good taste." Divergent validity evidence has been shown for the ASI through a negative correlation between both the eleven hostile sexism items and the eleven benevolent sexism items of the ASI and their correlation with the AWS ( $r=-.63$ and $r=$ .40 , respectively) (Glick \& Fiske, 1996).

NEO Personality Inventory 3. The NEO PI 3 (Costa \& McCrae, 1992) measures the five major domains of personality (Neuroticism, Extraversion, Openness, Agreeableness, and Conscientiousness) and the 30 facets that make up the domains. Internal consistency reliability for the NEO-PI-3 has been shown to range from .89 to .93 for the five domains and from .54 to .83 for the 30 facets (Costa \& McCrae, 1992). Evidence of convergent validity has been demonstrated through a positive correlation to other instruments assessing normal personality traits. Of the 50 item inventory, sample items include "I pay attention to details" (Conscientiousness), "I have excellent ideas" (Openness), "I am easily disturbed (Neuroticism), "I have a soft heart” (Agreeableness), and "I talk to a lot of different people at parties" (Extraversion). 


\section{Demographics}

Combining data from Studies I and II resulted in a dataset of 462 participants who ranged in age from 185-75, with the mean age range of 26-35 years of age. With regards to race, the participants reported being White/Caucasian (77.59\%), Hispanic/Latino (7.95\%), Asian (5.54\%), Black/African American (5.03\%), and other race (3.61\%). Ninety-three and seven tenths percent stated that they Heterosexual/Straight, $4.11 \%$ as Homosexual/Gay, and 2.81\% reported being Bisexual. On a scale of 1-8 where 1 represented a political affiliation of extremely liberal and 8 represented extremely conservative, the mean was near the middle $(M=4.42, S D=2.41)$. As far as highest level of education, a Bachelor's Degree was the most commonly reported (44.32\%), followed by Some College, No Degree (19.57\%), Associate Degree (13.67\%), Master's Degree (12.37\%), High School Diploma (9.61\%), and Doctorate (.46\%). Participants currently in management roles represented $47.41 \%$ of the sample, and $52.59 \%$ were not in management roles. Of the participants who reported being currently in management positions, $35.79 \%$ of the participants were managers at their current places of employment for 3-5 years, followed by $32.51 \%$ for $5-10$ years, $12.49 \%$ for $11-12$ years, $12.65 \%$ less than 2 years, and $6.56 \%$ at their jobs for 21 years or more. The participants worked for a variety of organizational sizes that ranged from self-employed to over 1000 employees with the average organizational size in the range of 100-249. For those participants that reported being currently in management roles, the average percentage of women they currently managed was $31.84 \%$. 


\section{Results}

Bivariate correlations were calculated to reflect the relationship between the M.A.W.W. and the other instruments included in Studies I and II. Significant positive correlations are evidence of convergent validity, and significant negative correlations are evidence of divergent validity for the overall validity of the M.A.W.W. The M.A.W.W. had a positive correlation with the AWS, $r=.67, p<.01$ and the Humanitarian Egalitarian Scale, $r=.46, p<.01$ and a negative correlation with the Neosexism Scale, $r=$ $-.69, p<.01$, the SDO, $r=-.86, p<.01$ and the ASI, $r=.-33, p<.01$. There were no significant correlations found between the M.A.W.W. and the extroversion factor of the NEO PI 3, further evidence of construct validity. Hypothesis 4 and its subparts $a, b$, and c are all supported. All correlation results among the measures in relation to the M.A.W.W. are shown in Table 6. 
Table 6.

Internal Consistency Reliability, Convergent, and Divergent Validity for Study 3.

\begin{tabular}{|c|c|c|c|c|c|c|c|c|c|c|}
\hline & 1 & 2 & 3 & 4 & 5 & 6 & 7 & 8 & 9 & 10 \\
\hline 1. M.A.W.W. & - & & & & & & & & & \\
\hline 2. M.A.W.W. Knowledge \& Awareness & $.91^{*}$ & - & & & & & & & & \\
\hline 3. M.A.W.W. Action & $.89^{*}$ & $.68^{*}$ & - & & & & & & & \\
\hline 4. M.A.W.W. Skills \& Capacity & $.75^{*}$ & $.39^{*}$ & $.51^{*}$ & - & & & & & & \\
\hline 5. AWS & $.67^{*}$ & $.60^{*}$ & $.72^{*}$ & $.57^{*}$ & - & & & & & \\
\hline 6. Neosexism & $-.69^{*}$ & $-.64^{*}$ & $-.28^{*}$ & $-.68^{*}$ & $-.31^{*}$ & - & & & & \\
\hline 7. SDO & $-.86^{*}$ & $-.65^{*}$ & $-.71^{*}$ & $-.91^{*}$ & $-.51^{*}$ & $.42^{*}$ & - & & & \\
\hline 8. Humanitarian Egalitarian Scale & $.46^{*}$ & $.33^{*}$ & $.25^{*}$ & $.54^{*}$ & $.45^{*}$ & $-.14^{*}$ & $-.27^{*}$ & - & & \\
\hline 9. ASI & $-.33^{*}$ & $-.25^{*}$ & $-.45^{*}$ & $-.35^{*}$ & $-.54^{*}$ & $.25^{*}$ & $.31^{*}$ & $-.48^{*}$ & - & \\
\hline 10. NEO PI 3 Extroversion & .24 & .12 & .41 & .16 & .25 & .28 & .20 & .30 & .34 & - \\
\hline$\alpha$ & .87 & .91 & .74 & .73 & .83 & .76 & .85 & .87 & .87 & .89 \\
\hline$M$ & 3.32 & 3.03 & 3.56 & 3.59 & 2.47 & 4.78 & 4.95 & 3.98 & 3.68 & 4.25 \\
\hline$S D$ & .75 & .50 & .68 & .74 & .57 & .64 & .95 & .31 & .54 & .64 \\
\hline Range & $1-5$ & $1-5$ & $1-5$ & $1-5$ & $1-4$ & $1-7$ & $1-7$ & $1-5$ & $1-6$ & $1-5$ \\
\hline
\end{tabular}


In addition to the demographic questions, the participants were also presented with a single, subjective item asking them whether they saw themselves as an ally to women at work. This item was "I am an ally to women in the workplace," and participants were asked to rate their agreement with this statement of a scale from 1 to 5 , where 1 represented strongly disagree and 5 represented strongly agree. Participants selfreported an ally mean score of $3.98(S D=.87)$, which was above the scale midpoint of 3 "Neither Disagree Nor Agree" and compared to their M.A.W.W. score $(M=3.32, S D=$ $.75)$, it was statistically significantly different, $t(386)=-.7 .96, p<.000$. The ally selfreport variable, as well as age, tenure, political affiliation, and educational level were analyzed in relation to each other and in relation to the M.A.W.W. scores through a correlation analysis. The results of the correlation study are provided in Table 7.

Table 7

Correlations of Key Demographics with the M.A.W.W.

\begin{tabular}{|c|c|c|c|c|c|c|}
\hline & M.A.W.W. & Age & Tenure & Pol. Aff. & $\begin{array}{c}\text { Ally } \\
\text { Self } \\
\text { Report }\end{array}$ & $\begin{array}{c}\text { Educ. } \\
\text { Lvl }\end{array}$ \\
\hline M.A.W.W. & --- & & & & & \\
\hline Age & $-.16^{*}$ & --- & & & & \\
\hline Tenure & $-.15 *$ & $.41 * * *$ & --- & & & \\
\hline Pol. Aff. & $-.87 * * *$ & $.20 * *$ & $.18 * *$ & --- & & \\
\hline Ally Self Report & -.04 & -.01 & $-.13 *$ & -.02 & --- & \\
\hline Educ. Lvl & -0.0 & .100491 & .04 & -.03 & $.13 *$ & --- \\
\hline \multicolumn{7}{|c|}{ Note. $* p<.05, * * p<.01, * * * p<.001$} \\
\hline \multicolumn{7}{|c|}{ Age and tenure demonstrated a significant relationship with the M.A.W.W. As } \\
\hline \multicolumn{7}{|c|}{ participants' age and tenure increased, participants' scores on the 15 -item M.A.W.W. } \\
\hline \multicolumn{7}{|c|}{ decreased. The relationship between political affiliation and the M.A.W.W. was } \\
\hline
\end{tabular}


political perspectives are more likely to be allies of women at work whereas men with conservative political perspectives are not.

Tenure, Age, and Political Affiliation. A multiple regression analysis was conducted using tenure, age, and political affiliation as simultaneous predictors of men's allyhood toward women in the workplace as reflected by the M.A.W.W.. The results are presented in Table 8 .

Table 8 .

Multiple Regression Analysis of Three Predictors of Allyhood

\begin{tabular}{lccccc}
\hline & $\mathrm{B}$ & $\mathrm{SE} \mathrm{B}$ & $\beta$ & $\mathrm{t}$ & $\mathrm{p}$ value \\
\cline { 2 - 6 } Age & -.003 & 0.028 & -0.003 & -0.088 & 0.929 \\
Tenure & .011 & 0.028 & 0.016 & 0.406 & 0.685 \\
Pol. Aff. & -.316 & 0.013 & $-0.874 *$ & -23.97 & .0000 \\
\hline
\end{tabular}

Note. $* p<.0000$. Pol. Aff. $\mathrm{r}^{2}=.76$.

The results show that political affiliation was the only statistically significant variable of the three, indicating that men's allyhood towards women at work can be predicted by their political affiliation. With a y intercept of 4.65 , the regression equation for the predictive relationship between political affiliation and the M.A.W.W. is $\mathrm{y}^{\wedge}=$ $4.65+(-.316 \mathrm{x})$, demonstrating that for every one unit increase in political affiliation there is likely to be a .316 decrease in men's allyhood toward women at work. Figure 3 shows a graph of the relationship where political affiliation predicts allyhood. 
Figure 3 .

Regression relationship between political affiliation and the M.A.W.W.

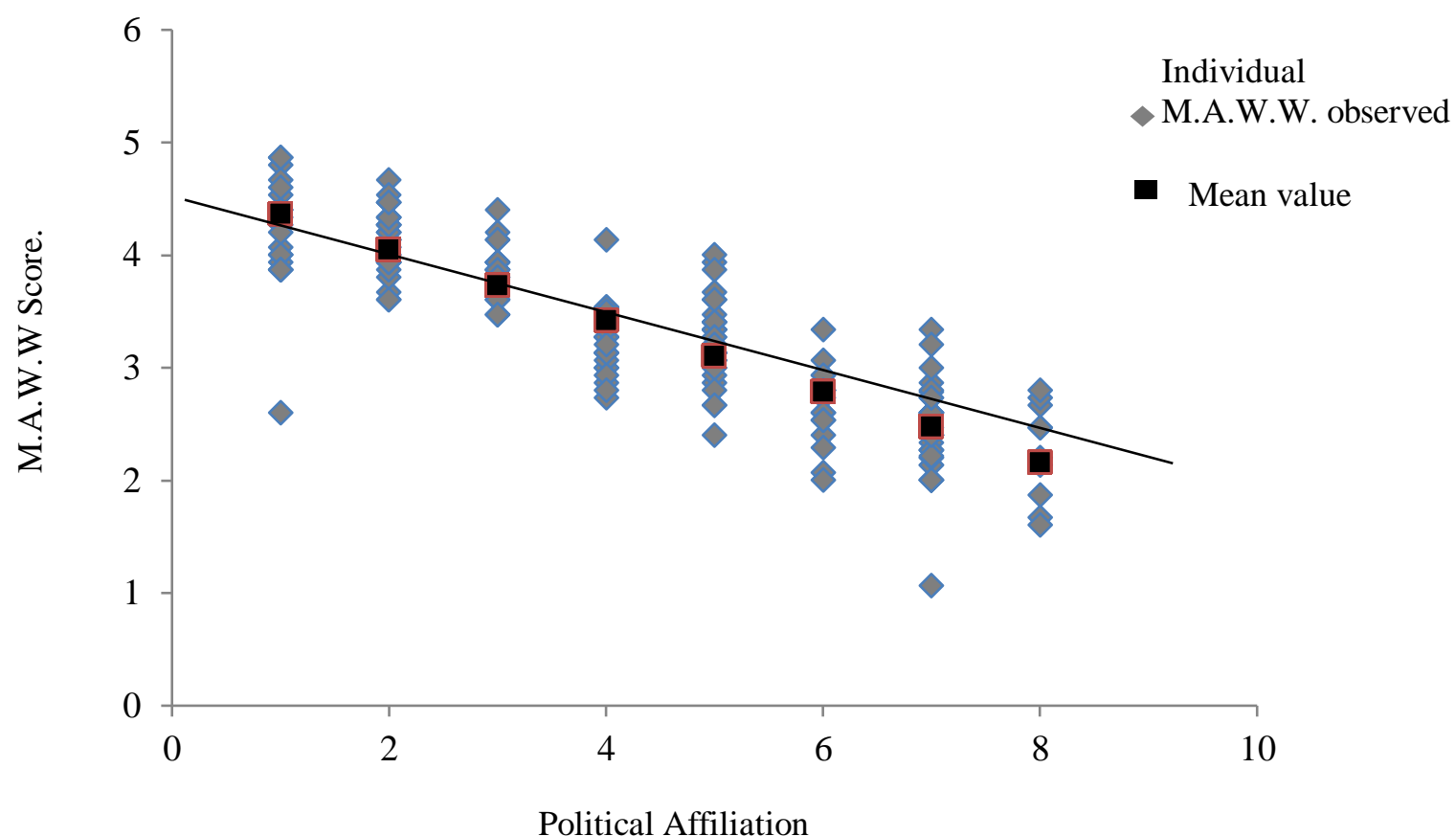

Political Affiliation and the M.A.W.W. Factors. To examine in additional detail the relationship between political affiliation and the M.A.W.W., linear regression analyses were conducted between political affiliation and each of the three factors of the M.A.W.W. A linear regression analysis between political affiliation and Knowledge \& Awareness yielded $\mathrm{B}=-1.82$, SE $\mathrm{B}=.10, \beta=-.806, t(191)=-18.97$, and $p<.000 . \mathrm{A}$ linear regression analysis between political affiliation and Action yielded B = -.18, SE B $=.02, \beta=-.569, t(191)=-9.60$, and $p<.000$. A linear regression analysis between political affiliation and Skills \& Capacity yielded $\mathrm{B}=-.32, \mathrm{SE} \mathrm{B}=.02, \beta=-.718, t(191)$ $=-14.28$, and $p<.000$. Looking at the coefficients $(\mathrm{B})$ of each of the three factors, political affiliation holds a greater predictive impact of the Knowledge \& Awareness factor $(\mathrm{B}=-1.82)$ of the M.A.W.W. as compared to the Action $(\mathrm{B}=-.18)$ and Skills \& Capacity $(\mathrm{B}=-.32)$ factors. 
Male Managers and Percentage of Women Managed. When only examining participants who were currently in managerial roles, a statistically significant correlation was demonstrated between the M.A.W.W. and the percentage of women managed, $r(92)$ $=.25, p<.01$. To investigate whether allyhood could be predicted by percentage of women managed, a simple linear regression analysis with the two variables was conducted and a statistically significant relationship was found $(\beta=.014, t(91)=2.51, p$ $=.01)$ with $R^{2}=.063, \mathrm{~F}(1,93)=6.30, p=.03$, meaning that the variable percentage of women managed explained $6.30 \%$ of the variance in the participants' responses to the M.A.W.W. With a y intercept of 3.16 a regression equation that represents allyhood being predicted by percentage of women managed is $\mathrm{y}^{\wedge}=3.16+.014 \mathrm{x}$, indicating that for every 1 unit increase in the percentage of women managed, there is a corresponding .014 increase in allyhood. By way of example, if Male Manager A manages a team that has no women members, it is predicted that Male Manager A would receive a M.A.W.W. score of 3.16. By way of comparison, if Male Manager B who manages a workforce composed of $40 \%$ women, it is predicted that Male Manager B would receive a M.A.W.W. score of 3.72, nearly half of a point increase on the M.A.W.W. scale.

\section{Pattern Invariance}

Pattern invariance refers to a statistical analysis that indicates whether or not that the same construct of a scale is being measured across different groups (Byrne, Shavelson, \& Muthen, 1989; Meredith, 1993; Schoot, Lugtig, \& Hox, 2012). Pattern invariance analysis follows the same steps for the CFA, but does so by comparing the fit indices of multiple subgroups and yielding a Chi Square value that indicates whether the fit indices differences among the different groups is statistically significant or not (Byrne 
et al., 1989). In the case of a pattern invariance analysis, a statistically non-significant result is evidence of the scale's stability (Vandenberg \& Lance, 2000). To examine the pattern invariance of the M.A.W.W. by participant age, an analysis was conducted using age as a group differentiator. There were six age groups: 18-24, 25-34, 35-44, 45-54, 5564 , and 65-75. The analysis yielded a $\chi^{2}(1, N=460)=12.75, p=.31$, indicating that the M.A.W.W. is stable across age groups. Similarly, a pattern invariance analysis was conducted using education as a group differentiator. There were six education groups: High school degree, Some college, Associate degree, Bachelor's degree, Master's degree, and Doctorate. The analysis yielded a $\chi^{2}(1, N=460)=8.43, p=.87$, indicating that the M.A.W.W. is defensible across educational groups too.

\section{DISCUSSION}

Four general dimensions of allyhood have emerged from prior research: Awareness, Knowledge, Skills, and Action (Bishop, 2002; Broido, 2000; Washington \& Evans, 1993). Yet despite the emergence of these dimensions, no quantitative research has sought to measure and understand the role of men as allies to women in the workplace. The present study sought to fill that gap and provide researchers and practitioners with a tool to identify men's allyhood toward women in the workplace, as well as to what degree of support men provide in a variety of domains.

For the present study it was hypothesized that there would be six distinct but related dimensions of men's allyhood towards women at work: Distal Awareness, Proximal Awareness, Knowledge, Social Support, Instrumental Support, and Action. Distal and Proximal Awareness were hypothesized to represent two subfacets of the dimension Awareness uncovered in prior research. Distal Awareness represented the 
notion in the development of allyhood that men recognize on a broad and abstract level that a patriarchy exists and that men in general are the beneficiaries of this societal system. Proximal Awareness represented the idea that on a more specific and concrete level, a man recognizes that he personally is a beneficiary, to varying degrees, of the patriarchy. The hypothesis that the original dimension Awareness may be better studied as two subfacets took shape because it seemed possible that a man could on one hand recognize that a patriarchy exists and that men in general are the beneficiaries, but on the other hand, he may not recognize that he himself benefits from the patriarchy to some degree. Likewise, the dimension Skills as presented in prior research was bifurcated in the present study to represent Social Support and Instrumental Support. Social Support referred to the empathetic and listening skills of men in relation to women at work facing circumstances of gender inequality. Instrumental Support referred men's capability to serve as a resource to women at work who ask for assistance when experiencing gender inequality. Thinking that it was conceivable that a man may be an effective listener but lack the resourcefulness to guide or assist women or vice versa, the idea that the dimension Skills would be better studied as two separate constructs took shape. This hypothesis that there would be six dimensions of allyhood regarding men's support and advocacy for women's equality at work was not supported by the results of an EFA.

The EFA conducted with 268 participants on 59 items in fact demonstrated that only three dimensions of allyhood exist which were then subsequently labeled:

Knowledge \& Awareness, Action, and Skills \& Capacity. A CFA conducted with 194 participants, using seventeen items supported this three factor solution for the M.A.W.W. and further analysis demonstrated a strong internal consistency reliability for the final 
fifteen item version of the M.A.W.W. Items originally thought to assess the hypothesized dimension of Knowledge and the hypothesized dimensions of Distal and Proximal Awareness loaded onto one factor. Items such as "I am familiar with a number of laws that give women protection from unequal treatment at work and "It is easier for a man to get to the top of an organization than it is for a woman because of sexism" correlated with the same factor, indicating participants' responses to these items was due to a common latent construct. That common latent construct was titled, Knowledge \& Awareness.

A second factor, Action, was uncovered by the EFA and confirmed by the CFA. Examining the items that make up the factor Action highlights the idea that the behaviors that men take in their support of women at work may vary in their degree of allyhood activity. For instance, both items "I am a member of a group that promotes women's workplace rights" and "If I see discrimination against a woman at work, I speak up against it" were grouped together by the EFA and CFA under the Action factor, but the former item does not necessarily suggest an overt or public act to the same degree as the later item might. That an ally's actions in support of women's gender equality at work varies in degrees is also reflected in the M.A.W.W. as a whole, as the M.A.W.W. is a measure based upon continuous variables that in the aggregate indicate a man's degree of allyhood, not a dichotomous outcome as to whether he is an ally or not.

The stage model of allyhood (e.g., Bishop, 2002; Broido, 2000) purports that persons pass through different stages of allyhood and become allies once they take action. In fact, some researchers suggest that the person must take multiple actions in support of women's equality for a person to be deemed an ally, the more overt the better (Broido, 
2000; Reason et al., 2005). Although the development and validation of the M.A.W.W. does not necessarily disagree with this process of allyhood development, what the development and validation of the M.A.W.W. demonstrates is that allyhood can also be viewed as a measure of the degree of allyhood, with the implication that stronger allies will be more supportive of gender equality at work. This viewpoint allows for a greater acceptance and inclusion of allies, recognizing that allies occupy various roles to various degrees.

Skills \& Capacity was the third factor demonstrated by the EFA and confirmed by the CFA. Items such as "If asked, I can direct a woman who may have a problem to the key people at work who may be of help" and "If approached by a woman at work who was experiencing discrimination, I have the skills to be able to talk with her about it" relate to a man's skillset and ability to assist women should a request arise. Originally, the former item was hypothesized to fall under the proposed dimension of Instrumental Support and the latter under Social Support, but the EFA and CFA grouped these items together suggesting that a single unified dimension of Skills \& Capacity was warranted. In the end, the final version of the M.A.W.W. was composed of fifteen items grouped under three factors.

Having a three factor outcome is not uncommon in research. Jones et al., (2014) developed and validated a scale to identify heterosexuals who were allies to members of the lesbian, gay, bisexual, and transgender (LGBT) community and hypothesized that there would be four factors: Awareness, Knowledge, Skills, and Action. After an EFA and CFA, three factors emerged which were named Knowledge \& Skills, Openness and Support, and Oppression Awareness. Items that were hypothesized to link to the proposed 
dimension Skills correlated with Knowledge items and Action items leading to the factor labels, Knowledge \& Skills and Openness \& Support.

Evidence of the M.A.W.W.'s validity was demonstrated by way of a convergent and divergent validity study. In both Studies I and II, the M.A.W.W. was administered alongside several other scales that were hypothesized to positively correlate or negatively correlate with the M.A.W.W.. Scales affirming support for gender equality such as the AWS and Humanitarian Egalitarian Scale yielded a positive correlation with the M.A.W.W., and scales that measure negative or prejudicial views toward women such as the SDO, Neosexism Scale, and the ASI yielded a negative correlation with the M.A.W.W. This positive and negative correlation analysis serves as support for the validity of the M.A.W.W. in that the M.A.W.W. is an effective tool in predicting a man's allyhood toward women at work. Furthermore, additional evidence of validity was demonstrated when the M.A.W.W. showed no correlation with the extroversion factor of the NEO PI 3, a personality factor that in past research has been shown to have no relationship with social justice scales or allyhood development scales (e.g. Jones et al., 2014). Additionally, with the M.A.W.W. having a moderately strong correlation with the AWS and a weak to moderate relationship with the Humanitarian Egalitarian Scale, both of which are not work-specific scales, the lack of complete correlational overlap between the M.A.W.W. and these other scales is evidence of the M.A.W.W.'s differential contribution to research as a tool that predicts allyhood. If the M.A.W.W. and the AWS and the Humanitarian Egalitarian Scale were to have correlations >.90 (Evans, 1996), then the M.A.W.W. would be redundant for all practical purposes (Cohen, 1992; Evans, 1996; Valente, Coronges, Laker, \& Costenbader, 2008). However, the correlations 
between the M.A.W.W. and the AWS and the Humanitarian Egalitarian Scale are less than .90 , reinforcing the notion that the M.A.W.W. has its proper place in social justice research.

In addition to the correlational relationships with other instruments, the M.A.W.W. also demonstrated a relationship to other variables such as political affiliation and percentage of women managed. Two separate linear regression analyses showed that both political liberalism and a man's experience in managing women at work predict the likelihood of men's allyhood toward women in the workplace. Although the link between political affiliation and men's view of gender equality is a robust and common finding in the social justice literature (e.g., Ciabattari, 2001; Davies, 2004; Denton, 2004; Wade, 2001), and further evidence of the M.A.W.W.'s validity, the link between political affiliation and the M.A.W.W.'s factors offers additional insight. Results of the present study demonstrated that men's political affiliation predicts the factor Knowledge \& Awareness more so than it predicts Action and Skills \& Capacity, and this finding is an indication that political liberal men may be stronger allies to women at work as compared to politically conservative men because they are more attune to the history, laws, and norms of gender equality in the context of a patriarchal system, more so than any other dimension.

The importance of the link between male managers and the percentage of women they manage as it relates to allyhood can be found in its predictive value. The present study has shown that the greater a percentage of women that a man supervises at work, the more likely he will be an ally toward women in the workplace. This predictive link holds practical value for organizations in that hiring committees comparing male 
candidates for managerial roles can foresee a candidate's allyhood based upon the percentage of women he has managed in prior employment roles. Although it is reasonable to surmise that gender equality-minded male managers may opt into roles that involve the management of women, and therefore, his experience supervising women is not the reason for his allyhood development, the fact still remains that the percentage of women managed predicts the degree of men's allyhood toward women at work. This link between managers and allyhood has been supported by prior research that has demonstrated that avoiding sexism and supporting working mothers has translated into success for gender diverse organizations (Brough \& O’Driscoll, 2010; Eby, Casper, Bordeaux, \& Brinley, 2005).

The results from the present study also demonstrated a statistically significant difference between to what degree participants self-identified as an ally to women at work and the actual degree of their allyhood as captured by M.A.W.W. scores. Participants tended to rate themselves more of ally than the M.A.W.W. identified. Although the notion that allies tend to overestimate their allyhood towards outgroup members is a prevalent theory in research (Cheng, 2018; Ji, 2007), this finding fills a gap in the literature by providing empirical evidence of this difference and to what degree that difference is. In short, men inflate their understanding of their allyhood toward women at work by $17 \%$. This particular finding empirically supports the theory that allies in general overestimate their allyhood. 


\section{LIMITATIONS AND DIRECTIONS FOR FUTURE RESEARCH}

\section{Limitations}

There are areas in the present study and more specifically, in the development and the validation of the M.A.W.W., that should be understood in light of its limitations and directions for future research. The M.A.W.W. in both Studies I and II used Amazon's MTurk system, and as such, the participant field was limited to only those individuals that have access to computers and the internet, and those participants who are computer literate. Future research would aid in the ongoing gathering of validity evidence of the M.A.W.W. by incorporating a broader demographic to ensure that the M.A.W.W. is generalizable to a broader spectrum of men regardless of their socio-economic status. Additionally, the present study administered the M.A.W.W. to men across a variety of organizations, whereas future research that limits the administration of the M.A.W.W. to a single organization could produce findings that speak toward organizational culture and climate.

Another limitation to this study is the absence of examining the M.A.W.W. itself as a predictor of actual ally behaviors. Inferences can be made that certain variables such as the three factors that make up the M.A.W.W., political affiliation, and the percentage of women managed predict allyhood, but the question of what allyhood toward women at work itself predicts in terms of social interactions with outgroup members and acts of advocacy on behalf of outgroup members remains unanswered for now.

The present study also is limited with regard to how it explored a participant's knowledge of the history, laws, and norms about gender equality. The M.A.W.W. presented items as to whether participants were familiar with laws and studies regarding 
gender equality in a general sense, but there was no link to the participants' specific place of work or a specific organizational policy. Furthermore, there was no actual assessment of the participants' actual knowledge, just their self-reporting as to whether they believed they were knowledgeable about gender equality at work topics.

Lastly, the present study lacks the inclusion of a social desirability scale whose results would have given a more meaningful interpretation to the present study's results. Social desirability scales are designed to detect whether respondents inflate their responses so as to appear to be socially acceptable or to gain social approval (Crowne \& Marlow, 1960). The M.A.W.W. did present participants with items regarding the gender equality, a construct where it is conceivable that some men may not support, yet would be reluctant to be overtly against. With the inclusion of a social desirability scale, a correlation analysis with allyhood could have been conducted to see whether or not the participants in the present study were motivated to distort their responses.

\section{Directions for Future Research}

Further research is recommended to continue to explore the effects of knowledge of gender equality history, laws, and norms at work and an awareness of the patriarchal system and how these aspects of allyhood development may be more impactful. Programs, curriculum, and interventions in the workplace may be well served by understanding that although multiple dimensions affect allyhood, some dimensions produce a greater effect than others. Along these lines, future research is needed that explores the M.A.W.W. ability as a tool to measure the effectiveness of workplace interventions that are designed to develop workplace allies. Now that a tool exists to measure men's allyhood toward women at work, the M.A.W.W. can be administered to 
measure before and after effects of gender equality workplace interventions. Human Resource initiatives that seek to promote workplace gender equality will now able to see if their programs, workshops, and curriculums are making a difference.

Future research is called for that validates or that may modify the M.A.W.W. to measure women's allyhood to other women at work. Research along these lines may explore women's allyhood toward women in general, women manager as allies to women direct reports, or women as allies to women managers. Further still, future research that studies the intersectionality (Crenshaw, 1989) of men's multiple social identities may shed additional light on men's understanding of the all three factors that make up the M.A.W.W.. Many men themselves possess a stigmatized identity (e.g. nonwhite race, homosexual, not fully able bodied), and therefore, experience oppression along with their male privilege, and these identities differ in saliency in different contexts (Liu, 2017). Factors at work that increase or decrease the saliency of these different identities may hold clues to understanding in what ways and to what degree men with stigmatized identities support women at work. Future research may also explain the relationship between men with stigmatized identities and white women and/or heterosexual women who experience privilege to some degree.

The present study explored the allyhood of male managers of women, but future research that studies the allyhood of men in relation to their female peers, not solely their direct reports, could produce different findings because the context has changed. Men's allyhood toward women at work could change when studied in association to female peers because limited resources, finite opportunities for advancement, and other elements that spur competition may be introduced. In other words, does the allyhood of men 
toward women at work hold steady or vary when his personal interests are at stake?

Studying this phenomenon in the context of team oriented versus outcome oriented organizations would further uncover the degree of influence personal interest has on men's allyhood toward women at work.

Further research is also needed to more fully understand why men inflate their self-awareness of allyhood towards women at work. Research directed towards investigating the reasons why men believe they are allies may shed light on why they tend to rate their allyhood to a far greater degree than it actual is.

\section{References}

Adams, G. A., King, L. A., \& King, D. W. (1996). Relationships of job and family involvement, family social support, and work-family conflict with job and life satisfaction. Journal of Applied Psychology, 81(4), 411-420. doi:10.1037/00219010.81.4.411

Amanatullah, E. T., \& Morris, M. W. (2010). Negotiating gender roles: Gender differences in assertive negotiating are mediated by women's fear of backlash and attenuated when negotiating on behalf of others. Journal of Personality and Social Psychology, 98(2), 256-267. doi:10.1037/a0017094

Asta, E. L., \& Vacha-Haase, T. (2013). Heterosexual ally development in counseling psychologists. The Counseling Psychologist, 41(4), 493-529.

Ayvazian, A. (1995). Interrupting the cycle of oppression: The role of allies as agents of change. Fellowship, 61(1-2), 6. Retrieved from https://search.proquest.com/docview/1936497385

Barbulescu, R., \& Bidwell, M. (2013). Do women choose different jobs from men? mechanisms of application segregation in the market for managerial workers. Organization Science, 24(3), 737-756. doi:10.1287/orsc.1120.0757

Beere, C., King, D., Beere, D., \& King, L. (1984). The sex-role egalitarianism scale: A measure of attitudes toward equality between the sexes. Sex Roles, 10(7-8), 563. doi:10.1007/BF00287265

Bell, L. A. (2007). Theoretical foundations for social justice education. In M. Adams, L. A. Bell, \& P. Griffin (Eds.), Teaching for diversity and social justice (pp. 1-14). New York, NY, US: Routledge/Taylor \& Francis Group. 
Bem, S. L. (1993). The lenses of gender: Transforming the debate on sexual inequality. New Haven, CT: Yale Univ. Press

Bishop, A. (2002). Becoming an ally: Breaking the cycle of oppression in people (2nd ed.). London; New York : Halifax, N.S. : New York: Zed Books; Fernwood Pub.; Distributed in the USA exclusively by Palgrave.

Bowles, H. R., Babcock, L., \& Lai, L. (2007). Social incentives for gender differences in the propensity to initiate negotiations: Sometimes it does hurt to ask. Organizational Behavior and Human Decision Processes, 103(1), 84-103. doi:10.1016/j.obhdp.2006.09.001

Brannon, R., \& Juni, S. (1984). A scale for measuring attitudes about masculinity. Psychological Documents, 14 (Doc. \#2612).

Broido, E. M. (2000). The development of social justice allies during college: A phenomenological investigation. Journal of College Student Development, 41(1), 3. Retrieved from https://search.proquest.com/docview/1416092998

Brown, C. S. (2002). Refusing racism : White allies and the struggle for civil rights. New York: Teachers College Press. Strauss, A.

Byrne, B. M. (2010). Structural equation modeling with AMOS (2. ed., reprint. ed.). New York [u.a.]: Psychology Press.

Byrne, B. M., Shavelson, R. J., \& Muthén, B. (1989). Testing for the equivalence of factor covariance and mean structures. Psychological Bulletin, 105(3), 456-466. doi:10.1037/0033-2909.105.3.456

Campbell, B., Schellenberg, E. G., \& Senn, C. Y. (1997). Evaluating measures of contemporary sexism. Psychology of Women Quarterly, 21(1), 89-102. doi:10.1111/j.1471-6402.1997.tb00102.x

Caldwell, J. C., \& Vera, E. M. (2010). Critical incidents in counseling psychology professionals' and trainees' social justice orientation development. Training and Education in Professional Psychology, 4(3), 163-176. doi:10.1037/a0019093

Caltabiano, M. L., Bryne, D., \& Sarafino, E. P. (2002). Health psychology: Biopsychosocial interactions. an australian perspective John Wiley \& Sons.

Case, K. A. (2012). Discovering the privilege of whiteness: White women's reflections on anti-racist identity and ally behavior. Journal of Social Issues, 68(1), 78-96. doi:10.1111/j.1540-4560.2011.01737.x 
Case, K. A., Hensley, R., \& Anderson, A. (2014). Reflecting on heterosexual and male privilege: Interventions to raise awareness. Journal of Social Issues, 70(4), 722740. doi:10.1111/josi.12088

Cheung, J. H., Burns, D. K., Sinclair, R. R., \& Sliter, M. (2017). Amazon mechanical turk in organizational psychology: An evaluation and practical recommendations. Journal of Business and Psychology, 32(4), 347-361. doi:10.1007/s10869-016-9458-5

Churchill, G. A. (1979). A paradigm for developing better measures of marketing constructs. Journal of Marketing Research, 16(1), 64-73. http://dx.doi.org/10.2307/3150876

Ciabattari, T. (2001). Changes in men's conservative gender ideologies: Cohort and period influences. Gender and Society, 15(4), 574-591. doi:10.1177/089124301015004005

Cohen, J. (1988). Statistical power analysis for the behavioral sciences (Second edition ed.). New York: Psychology Press.

Cohen, R., \& Zelnik, R. E. (2002). The free speech movement: Reflections on Berkeley in the 1960s. Retrieved from http://search.ebscohost.com/login.aspx ?direct=true\&scope=site $\& \mathrm{db}=$ nlebk\& $\underline{\mathrm{db}}=$ nlabk\&AN=108442

Correll, S., Benard, S., \& Paik, I. (2007). Getting a job: Is there a motherhood penalty? The American Journal of Sociology, 112(5), 1297-1339. doi:10.1086/511799

Costa, P. T., \& McCrae, R. R. (1992). Normal personality assessment in clinical practice. Psychological Assessment, 4(1), 5-13. doi:10.1037/1040-3590.4.1.5

Cronbach, L. J. (1951). Coefficient alpha and the internal structure of tests. Psychometrika, 16(3), 297-334.

Davies, M. (2004). Correlates of negative attitudes toward gay men: Sexism, male role norms, and male sexuality. Journal of Sex Research, 41(3), 259-266. doi:10.1080/00224490409552233

Davis, T. L., \& Wagner, R. (2005). Increasing men's development of social justice attitudes and actions. New Directions for Student Services, 2005(110), 29-41. doi:10.1002/ss.163

Declercq, F. D. R., Vanheule, S., Markey, S., \& Willemsen, J. (2007). Posttraumatic distress in security guards and the various effects of social support. Journal of Clinical Psychology, 63(12), 1239-1246. doi:10.1002/jclp.20426 
Denison, D. R. (1996). What is the difference between organizational culture and organizational climate? a native's point of view on a decade of paradigm wars. Academy of Management Review, 21(3), 619-654. doi:10.5465/AMR.1996.9702100310

Denton, M. L. (2004). Gender and marital decision making: Negotiating religious ideology and practice. Social Forces, 82(3), 1151-1180. doi:10.1353/sof.2004.0034

DeVellis, R. F. (2003). Scale development: Theory an applications. Thousand Oaks, Calif. u.a: SAGE. Retrieved from http://www.fachportalpaedagogik.de/fis_bildung/suche/fis_set.html?FId=918030

Diekman, A. B., Brown, E. R., Johnston, A. M., \& Clark, E. K. (2010). Seeking congruity between goals and roles: A new look at why women opt out of science, technology, engineering, and mathematics careers. Psychological Science, 21(8), 1051-1057. doi:10.1177/0956797610377342

DiStefano, T. M., Croteau, J. M., Anderson, M. Z., Kampa-Kokesch, S., \& Bullard, M. A. (2000). Experiences of being heterosexual allies to lesbian, gay, and bisexual people: A qualitative exploration. Journal of College Counseling, 3(2), 131-141. doi:10.1002/j.2161-1882.2000.tb00173.x

Domino, G., \& Domino, M. L. (2006). Psychological testing (2. ed. ed.). Cambridge [u.a.]: Cambridge Univ. Press.

Eagly, A. H. (2013). Women as leaders: Leadership style versus leaders' values and attitudes. In Ely, R. J., \& Cuddy, A. J. C. (Eds.), Gender and work: Challenging conventional wisdom (pp. 4-11). Boston, MA: Harvard Business School Press.

Eagly, A. H., \& Carli, L. L. (2007). Through the labyrinth: The truth about how women become leaders. Boston, Mass: Harvard Business School Pr.

Eagly, A. H., \& Karau, S. J. (2002). Role congruity theory of prejudice toward female leaders. Psychological Review, 109(3), 573-598. doi:10.1037//0033295X.109.3.573

Edwards, K. E. (2007). Aspiring social justice ally identity development: A conceptual model. NASPA Journal, 43(4), 4. doi:10.2202/0027-6014.1722

Fassinger, R. E. (1994). Development and testing of the attitudes toward feminism and the women's movement (FWM) scale. Psychology of Women Quarterly, 18(3), 389-402. doi:10.1111/j.1471-6402.1994.tb00462.x 
Furr, R. M., \& Bacharach, V. R. (2008). Psychometrics: An introduction. Thousand Oaks, CA, US: Sage Publications, Inc.

Gelberg, S., \& Chojnacki, J. T. (1995). Developmental transitions of gay/lesbian/bisexual-affirmative, heterosexual career counselors. The Career Development Quarterly, 43(3), 267-273. doi:10.1002/j.2161-0045.1995.tb00867.x

Getz, C. \& Kirkley, E. A. (2003). Identity Development Models: One size fits all? Heterosexual identity development and the search for "Allies" in higher education.

Gibson, J. L., Payne, S. C., Morgan, W. B., \& Allen, J. A. (2018). The society for industrial and organizational psychology's guidelines for education and training: An executive summary of the 2016/2017 revision. The American Psychologist, 73(5), 678-682. doi:10.1037/amp0000266

Gipson A. N., Pfaff, D. L., Mendelsohn, D. B., Catenacci, L. T., \& Burke, W. W. (2017). Women and leadership. The Journal of Applied Behavioral Science, 53(1), 32-65. 10.1177/0021886316687247 Retrieved from http://journals.sagepub.com/doi/full/10.1177/0021886316687247

Glick, P., \& Fiske, S. T. (1997). Hostile and benevolent sexism. Psychology of Women Quarterly, 21(1), 119-135. doi:10.1111/j.1471-6402.1997.tb00104.x

Gonzalez, J. A., \& Denisi, A. S. (2009). Cross-level effects of demography and diversity climate on organizational attachment and firm effectiveness. Journal of Organizational Behavior, 30(1), 21-40. doi:10.1002/job.498

Goodman, D. J. (2001). Promoting diversity and social justice. Thousand Oaks [u.a.]: Sage Publ.

Gorsuch, R. L. (1990). Common factor analysis versus component analysis: Some well and little known facts. Multivariate Behavioral Research, 25(1), 33-39. doi:10.1207/s15327906mbr2501_3

Hair, J. F., Anderson, R. E., Tatham, R. L., \& Black, W. C. (1995). Multivariate data analysis. Englewood Cliffs, NJ: Prentice-Hall.

Hair, J. F., Black, W. C., Babin, B. J., \& Anderson, R. E. (2019). Multivariate data analysis (eighth edition ed.). Andover, Hampshire, UK: Cengage Learning, EMEA.

Hardiman, R., \& Jackson, B. W. (1992). Racial identity development: Understanding racial dynamics in college classrooms and on campus. New Directions for Teaching and Learning, 1992(52), 21-37. doi:10.1002/t1.37219925204 
Heilman, M. E. (2012). Gender stereotypes and workplace bias. Research in Organizational Behavior, 32, 113-135. doi:10.1016/j.riob.2012.11.003

Herbenick, D. L. (2007). The development and validation of a scale to measure college students' attitudes toward women's genitals Available from ProQuest Health \& Medical Complete (Alumni). Retrieved from https://search.proquest.com/docview/304855847

Hinkin, T. R. (1995). A review of scale development practices in the study of organizations. Journal of Management, 21(5), 967-988. doi:10.1177/014920639502100509

House, J. S. (1981). Work stress and social support. Reading, Mass. [u.a]: AddisonWesley. Retrieved from http://www.econis.eu/PPNSET?PPN=021826234

John, O. R., \& Benet-Martinez, V. (2000). Measurement: Reliability, construct validation, and scale construction. In H. T. Reis, \& C. M. Judd (Eds.) Handbook of research methods in social and personality psychology (pp. 339-369). New York: Cambridge University Press.

Jones, M. H. (2014). Knowledge, power, and black politics. Albany, NY: State Univ. of New York Press.

Joshi, A., Son, J., \& Roh, H. (2015). When can women close the gap? A meta-analytic test of sex differences in performance and rewards.Academy of Management Journal, 58(5), 1516-1545. doi:10.5465/amj.2013.0721

Katz, I., \& Hass, R. G. (1988). Racial ambivalence and american value conflict. Journal of Personality and Social Psychology, 55(6), 893-905. doi:10.1037/00223514.55.6.893

Kim, J., \& Mueller, C. W. (1978). Factor analysis: Statistical methods and practical issues. Beverly Hills, Cal: Sage.

Kim, J., \& Mueller, C. W. (1978). Introduction to factor analysis (6. Aufl. ed.). Beverly Hills [u.a.]: Sage Publ.

King, E. B., Hebl, M. R., George, J. M., \& Matusik, S. F. (2010). Understanding tokenism: Antecedents and consequences of a psychological climate of gender inequity. Journal of Management, 36(2), 482-510. doi:10.1177/0149206308328508

King, C., Phillips, C., Walker, K. D., \& K. O'Toole, S. (2014). A reliability generalization of the attitudes toward women (AWS) scale. Race, Gender \& Class, 21(1/2), 151-168. Retrieved from https://www.jstor.org/stable/43496966 
Kossek, E. E., Rong Su, \& Lusi Wu. (2017). "Opting out" or "pushed out"? integrating perspectives on women's career equality for gender inclusion and interventions. Journal of Management, 43(1), 228. doi:10.1177/0149206316671582

Krishnan, H. A., \& Park, D. (2005). A few good women-on top management teams. Journal of Business Research, 58(12), 1712-1720. doi:10.1016/j.jbusres.2004.09.003

Kumar, M. S., \& Kamalanabhan, T. (2014). Initial development and validation of a measure of intercultural development scale. Psychological Studies, 59(1), 52-58. doi:10.1007/s12646-014-0238-x

Leslie, L. M., Manchester, C. F., \& Dahm, P. C. (2017). Why and when does the gender gap reverse? diversity goals and the pay premium for high potential women. Academy of Management Journal, 60(2), 402-432. doi:10.5465/amj.2015.0195

Likert, R. (1932). A technique for the measurement of attitudes. New York: Univ.

Litman, L., Robinson, J., \& Abberbock, T. (2017). TurkPrime.com: A versatile crowdsourcing data acquisition platform for the behavioral sciences. Behavior Research Methods, 49(2), 433-442. doi:10.3758/s13428-016-0727-z

Lueptow, L. B., Garovich-Szabo, L., \& Lueptow, M. B. (2001). Social change and the persistence of sex typing: 1974-1997. Social Forces, 80(1), 1-36. doi:10.1353/sof.2001.0077

Lugtig, P., \& Hox, J. (2012). A checklist for testing measurement invariance AU - van de schoot, rens. European Journal of Developmental Psychology, 9(4), 486-492. doi:10.1080/17405629.2012.686740

Liu, W. M. (2017). White male power and privilege: The relationship between White supremacy and social class. Journal of Counseling Psychology, 64(4), 349358. doi: $0.1037 / \mathrm{cou} 0000227$

MacCallum, R. C., Browne, M. W., \& Sugawara, H. M. (1996). Power analysis and determination of sample size for covariance structure modeling. Psychological Methods, 1(2), 130-149. doi:10.1037/1082-989X.1.2.130

McConahay, J. B. (1986). Modern Racism, Ambivalence, and the Modern Racism Scale. In J. F. Dovidio \& S. L. Gaertner (Eds.), Prejudice, Discrimination, and Racism (pp. 91-125). San Diego, CA: Academic Press.

McLeod, S. A. (2007). What is reliability?. Retrieved from https://www.simplypsychology.org/reliability.html 
Michailidis, M. P., Morphitou, R. N., \& Theophylatou, I. (2012). Women at work equality versus

inequality: Barriers for advancing in the workplace. International Journal of Human Resource Management, 23, 4231-4245. https://doi.org/10.1080/09585192.2012.665071

Mio, J. S., \& Roades, L. A. (2003). Building bridges in the 21st century: Allies and the power of human connection across demographic divides. Culturally diverse mental health: The challenges of research and resistance, (pp. 105-117). New York: Brunner-Routledge.

Munin, A., \& Speight, S. L. (2010). Factors influencing the ally development of college students. Equity \& Excellence in Education, 43(2), 249-264. doi:10.1080/10665681003704337

Nunnally, J. C. (1978). Psychometric theory (2.ed. ed.). New York [u.a.]: McGraw-Hill.

Organ, D. W. (1988). Issues in organization and management series. Organizational citizenship behavior: The good soldier syndrome. Lexington, MA, England: Lexington Books/D. C. Heath and Com.

Osborne, J. W., \& Costello, A. B. (2009). Best practices in exploratory factor analysis: Four recommendations for getting the most from your analysis. Pan-Pacific Management Review, 12(2), 131-146. Retrieved from http://www.hyread.com.tw/hypage.cgi?HYPAGE=search/search_detail_new .hpg\&dtd_id=3\&sysid=00157611

Paustian-Underdahl, S. C., Eaton, A. A., Mandeville, A., \& Little, L. M. (2019). Pushed out or opting out? integrating perspectives on gender differences in withdrawal attitudes during pregnancy. The Journal of Applied Psychology, doi:10.1037/ap10000394

Petty, R. E., Cacioppo, J. T., Strathman, A. J., \& Priester, J. R. (2005). To think or not to think: Exploring two routes to persuasion. In T. C. Brock, \& M. C. Green (Eds.), 2nd ed.; persuasion: Psychological insights and perspectives (2nd ed. ed., pp. 81-116, Chapter xi, 353 Pages) Sage Publications, Inc, Thousand Oaks, CA.

Phelan, J. E., \& Rudman, L. A. (2010). Prejudice toward female leaders: Backlash effects and women's impression management dilemma.Social and Personality Psychology Compass, 4(10), 807-820. doi:10.1111/j.1751-9004.2010.00306.x

Ployhart, R. E., \& Holtz, B. C. (2008). The diversity-validity dilemma: Strategies for reducing racioethnic and sex subgroup differences and adverse impact in selection. Personnel Psychology, 61(1), 153-172. doi:10.1111/j.17446570.2008.00109.x 
Podsakoff, P. M. (2003). How to 'break down' a Theoretical Construct and its Measures. Indiana University, Bloomington.

Poteet, M. L., Parker, B. N., Herman, A. E., DuVernet, A., \& Conley, K. M. (2017). Society for Industrial and Organizational Psychology (SIOP) 2016 salary survey. Retrieved from http://www.siop.org/tip/Jan17/Report.pdf

Pratto, F., Sidanius, J., Stallworth, L. M., \& Malle, B. F. (1994). Social dominance orientation. Journal of Personality and Social Psychology, 67(4), 741-763. doi:10.1037/0022-3514.67.4.741

Preacher, K. J., \& MacCallum, R. C. (2003). Repairing tom swift's electric factor analysis machine. Understanding Statistics, 2(1), 13-43. doi:10.1207/S15328031US0201_02

Rea, L. M., \& Parker, R. A. (1999). Designing and conducting survey research : A comprehensive guide. New York, NY: Wiley. Retrieved from https://ebookcentral.proquest.com/lib/[SITE ID]/detail.action?docID=70031 $\underline{0}$

Reason, R. D., Roosa Millar, E. A., \& Scales, T. C. (2005). Toward a model of racial justice ally development. Journal of College Student Development, 46(5), 530546. doi:10.1353/csd.2005.0054

Reynolds, A. L., \& Pope, R. L. (1991). The complexities of diversity: Exploring multiple oppressions. Journal of Counseling \& Development, 70(1), 174-180. doi:10.1002/j.1556-6676.1991.tb01580.x

Rominger, A. S., \& Sandoval, P. (1998). Employee testing: Reconciling the twin goals of productivity and fairness. DePaul Business Law Journal, 10, 299.

Rosseel, Y. (2012). Lavaan: An R package for structural equation modeling. Journal of Statistical Software, 48(2) doi:10.18637/jss.v048.i02

Rudman, L. (2004). Social justice in our minds, homes, and society: The nature, causes, and consequences of implicit bias. Social Justice Research, 17(2), 129-142. doi:SORE.0000027406.32604.f6

Rudman, L. A., \& Glick, P. (2001). Prescriptive gender stereotypes and backlash toward agentic women. Journal of Social Issues, 57(4), 743-762. doi:10.1111/00224537.00239

Sarafino, E. P. (2006). Health psychology (5. ed. ed.). Hoboken, NJ: Wiley. 
Schmitt, N. (1996). Uses and abuses of coefficient alpha. Psychological Assessment, 8(4), 350-353. http://dx.doi.org/10.1037/1040-3590.8.4.350

Schneider, B., Ehrhart, M. G., \& Macey, W. H. (2013). Organizational climate and culture (1. publ. ed.), 64, 361-388.

Schneider, B., White, S. S., \& Paul, M. C. (1998). Linking service climate and customer perceptions of service quality. Journal of Applied Psychology, 83(2), 150-163. doi:10.1037/0021-9010.83.2.150

Sears, D. 0. (1988). Symbolic racism. In P. S. Katz \& D. A. Taylor (Eds.), Eliminating racism: Profiles in controversy (p. 123-151). New York: Plenum.

Semmer, N. K., Elfering, A., Jacobshagen, N., Perrot, T., Beehr, T. A., \& Boos, N. (2008). The emotional meaning of instrumental social support. International Journal of Stress Management, 15(3), 235-251. doi:10.1037/1072-5245.15.3.235

Shadish, W. R., Cook, T. D., \& Campbell, D. T. (2002). Experimental and quasiexperimental designs for generalized causal inference. Boston [u.a.]: Houghton Mifflin.

Shakespeare-Finch, J., \& Obst, P. L. (2011). The development of the 2-way social support scale: A measure of giving and receiving emotional and instrumental support. Journal of Personality Assessment, 93(5), 483-490. doi:10.1080/00223891.2011.594124

Smith, L., \& Redington, R. M. (2010). Lessons from the experiences of white antiracist activists. Professional Psychology: Research and Practice, 41(6), 541-549. doi:10.1037/a0021793

Spector, P. E. (1992). Summated rating scale construction. Newbury Park, CA: Sage. http://dx.doi.org/10.4135/9781412986038

Spence, J. T., \& Hahn, E. D. (1997). The attitudes toward women scale and attitude change in college students. Psychology of Women Quarterly, 21, 17-34. http://dx.doi.org/10.1111/j.1471-6402.1997.tb00098.x

Spence. J. T., \& Helmreich, R. (1972). The attitudes toward women scale: An objective instrument to measure attitudes toward the rights and roles of women in contemporary society. JSAS Catalog of Selected Documents in Psychology, 2, 66. https://doi.org/10.1111/j.1471-6402.1997.tb00098.x

Streiner, D. L. (2003). Starting at the beginning: An introduction to coefficient alpha and internal consistency. Journal of Personality Assessment, 80(1), 99-103. doi:10.1207/S15327752JPA8001_18 
Struwig, F. W., \& Stead, G. B. (2001). Planning, designing and reporting research. Cape Town: Pearson Education South Africa.

Tabachnick, B. G., \& Fidell, L. S. (2000). Using multivariate statistics: Pearson new international edition (International edition of sixth edition. ed.). Harlow, United Kingdom: Pearson Education. Retrieved from https://ebookcentral.proquest.com/lib/[SITE_ID]/detail.action?docID=51388 $\underline{76}$

Thompson, B. (2004). Exploratory and confirmatory factor analysis: Understanding concepts and applications. (1. ed., 2. printing ed.). Washington, DC: American Psychological Assoc.

Tougas, F., Brown, R., Beaton, A. M., \& Joly, S. (1995).Neosexism: Plus Fa change, plus c'est pareil. Personality and Social Psychology Buletin,21,842-849.

U.S. Department of Labor, Bureau of Labor Statistics. (2018). Librarians. Occupational outlook handbook, 2017-18.

U.S. Department of Labor, Bureau of Labor Statistics. (2017). Librarians. Occupational outlook handbook, 2015-16.

Vandenberg, R. J., \& Lance, C. E. (2000). A review and synthesis of the measurement invariance literature: Suggestions, practices, and recommendations for organizational research. Organizational Research Methods, 3(1), 4-70. oi:10.1177/109442810031002

Valente, T. W., Coronges, K., Lakon, C., \& Costenbader, E. (2008). How correlated are network centrality measures? Connections (Toronto, Ont.), 28(1), 16-26. Retrieved from http://ezproxy.fiu.edu/login?url=https://search-proquestcom.ezproxy.fiu.edu/docview/1835589253?accountid=10901

Wade, J. C. (2001). Professional men's attitudes toward race and gender equity. The Journal of Men's Studies, 10(1), 73-88. doi:10.3149/jms.1001.73

Wanberg, C. R., Welsh, E. T., \& Hezlett, S. A. (2003). Mentoring research: A review and dynamic process model. Research in personnel and human resources management. volume 22. 2003, pp. 39-124 (pp. 39-124)

Washington, J., \& Evans, N. J. (1991). Becoming an ally. In N. J. Evans \& V.A. Wall (Eds.), Beyond tolerance: Gavs. lesbians and bisexuals on campus (pp. 195-204). Washington, DC: American College Personnel Association.

Weston, R., \& Gore, P. A. (2006). A brief guide to structural equation modeling. The Counseling Psychologist, 34(5), 719-751. doi:10.1177/0011000006286345 
Williams, B., Brown, T., \& Onsman, A. (2010). Exploratory factor analysis: A five-step guide for novices. Australasian Journal of Paramedicine, 8(3).

Williams, M. J., \& Tiedens, L. Z. (2016). The subtle suspension of backlash: A metaanalysis of penalties for women's implicit and explicit dominance behavior. Psychological Bulletin, 142(2), 165. Retrieved

from https://www.ncbi.nlm.nih.gov/pubmed/26689089

Worthington, R. L., \& Whittaker, T. A. (2006). Scale development research: A content analysis and recommendations for best practices. Counseling Psychologist, 34(5), 806. Retrieved from https://search.proquest.com/docview/203271063

Wright, D. B., Eaton, A. A., \& Skagerberg, E. (2015). Occupational segregation and psychological gender differences: How empathizing and systemizing help explain the distribution of men and women into (some) occupations. Journal of Research in Personality, 54, 30-39. doi:10.1016/j.jrp.2014.06.004

Yi, J. (2009). A measure of knowledge sharing behavior. Knowledge Management Research \& Practice, 7(1), 65-81. 


\section{APPENDICES}

\section{APPENDIX A}

Item Pool for a Measure to Identify Men who are Allies of Women in the Workplace

Thank you for agreeing to review a preliminary list of items for a proposed measure to identify men who are allies of women in the workforce! The final version of this measurement will be validated on and administered to adult men who are employed.

Based on theories and measures of allyhood, such as LGBT allyhood (e.g., Jones, et al., 2014: Washington \& Evans, 1991), and research on sexism in the workplace (e.g., Leskinen, Cortina \& Kabat, 2011) we have developed six dimensions of allyhood development that assess various aspects of being a strong ally to women at work: (1) Distal Awareness, (2) Proximal Awareness, (3) Knowledge, (4) Social Support Skills, (5) Instrumental Support Skills, and (6) Action.

Presently, we are conceiving of these dimensions of allyhood as developing in parallel (though not perfectly independently). These six factors are NOT sequential stages of allyhood in a stage model; it is possible for an individual to have many combinations of high and low scores on these factors. Each factor may also have independent predictive value/validity, though higher scores on every factor are intended to indicate higher levels of the latent construct of "allyhood."

Overall, the purpose of the intended measure is to address the need for a tool to advance theory and practice on the nature, development, and utility of men allies of women at work. With regard to academic research, such a tool would allow for the study of the moderating effects of allyhood on the relationship between predictors related to women's 
advancement (e.g., the proportion of women in an organization) and workplace outcomes (e.g., the proportion of women in leadership positions). Additionally, this measure would allow practitioners to identify allies for selection purposes, for the formation of teams, and to evaluate the effectiveness of programs intended to increase allyhood and workplace climate for women.

Please review each item for its relevancy to its dimension. What will be of most use to us, however, will be your own comments and feedback on each item and on the measure as a whole. We are open to deleting, adding, and combining entire factors and items within $\underline{\text { factors. }}$

\section{Awareness}

Awareness of sexism and sexist oppression in the workplace is one feature male allies of women at work should possess. Prior research demonstrates that there may be two strands of awareness a developed ally can achieve. These two strands are differentiated by whether they are distally or proximally related to the ally.

The first strand of awareness - the distal form- involves the ally recognizing that his ingroup benefits to varying degrees from the oppression of the outgroup (Washington \& Evans, 1991). In other words, the more a man recognizes that men, in general, are systematically privileged in society as compared to women, the stronger he is in this strand of awareness.

The second strand of awareness in allyhood development - the proximal form - requires the ally to recognize introspectively that he, personally, has benefited to varying degrees from the systematic oppression of the outgroup (Bishop, 2002). In other words, the more 
a male ally recognizes that he personally is a beneficiary of the systemic oppression of women, the stronger he is in this form of awareness.

\section{Factor 1: Distal Awareness}

The distal strand of Awareness involves the ally recognizing that his ingroup benefits to varying degrees from the oppression of the outgroup (Washington \& Evans, 1991). In

other words, the more a man recognizes that men are systematically privileged in society as compared to women, the stronger he is in this strand of awareness.

(1) In general, women are not treated as favorably as men in the workplace.

(2) It is more difficult for women to advance in the workplace as compared to men.

(3) In general, women are paid less than men for the same job.

(4) At work, women are not compensated as much as men are.

(5) At work, women are not promoted as much as men are.

(6) Compared to women, I recognize that certain benefits at work come more easily to men.

(7) I believe women when they say there is sexism in the workplace.

(8) Sexism isn't a problem in modern-day organizations. (REVERSE)

(9) It's easier for a man to get to the top of an organization than it is for a woman, just because of his sex. 
(10) Women face challenges at work that men do not.

(11) When a man and woman are equally-qualified for a position, the man's sex puts him at an advantage.

(12) Women experience sexual harassment at work more often than men.

(13) Despite the many advances made towards gender equality in the last 50 years, there is still prejudice against women in the workplace.

(14) Men are usually assumed to be competent in their jobs, while women usually have to prove their competence.

***Feel free to add any comments here with regards to the factor Distal Awareness as it relates to the construct allyhood in general.

\section{Factor 2: Proximal Awareness}

The proximal strand of awareness requires the ally to recognize introspectively that he, personally, has benefited to varying degrees from the systematic oppression of the outgroup (Bishop, 2002). In other words, the more a male ally recognizes that he personally is a beneficiary of the systemic oppression of women, the stronger he is in this form of awareness.

(1) As a man I have privileges at work that my women colleagues do not.

(2) I recognize that certain benefits at work may come more easily to me as compared to my female coworkers.

(3) At work, I wouldn't get into as much trouble if I talked down to a woman than if I had talked down to another man. 
(4) Sometimes I wonder if I am paid more for my job than my female coworkers who do the same job.

(5) Sometimes I wonder if the good things that happen to me at work are because I am a man and not a woman.

(6) I think women face barriers in the workplace that I do not.

(7) Generally, I don't experience negative biases at work to the degree that women typically do.

$* * *$ Feel free to add any comments here with regards to the

factor Proximal Awareness as it relates to the construct allyhood in general.

\section{Factor 3: Knowledge}

Knowledge of the history of and remedies for sexism and sexist oppression in the workplace is another feature male allies of women at work should possess.

Knowledge/Education refers to the ally's knowledge and understanding of how laws, policies, practices, histories, culture, and norms affect women as compared to men in the workplace (Broido, 2000; Jones et al., 2014). Knowledge is different from Awareness in that, for instance, it is possible for a man to simultaneously rate himself high in his knowledge of laws that address employment discrimination of women, and low in his awareness that men as a group continue to benefit from the systemic oppression of women. Furthermore, Broido and Reason (2005) noted that confidence in one's knowledge of women at work demonstrated a stronger degree of allyhood.

(1) I am familiar with a number of laws that give women protection from unequal treatment at work. 
(2) There are laws on the books that require employers to pay women equal wages for the same job as men.

(3) There was a time in our history where custom did not allow women to be the boss.

(4) There was a time in our history where women were expected to quit their jobs when they got pregnant.

(5) There was a time in our history where women were expected to quit their jobs when they got married.

(6) There used to be a time in our history where women could be fired from their jobs if they took off time to have a baby.

(7) There really isn't a stigma that stays with a woman after a sexual harassment matter has been closed. (REVERSE)

(8) Most women who win or settle a case after being sexually harassed are better off because of the amount of money they received. (REVERSE)

(9) I am confident that I am up-to-date on the federal laws regarding discrimination in the workplace.

(10) I am confident that I am up-to-date on the policies at my workplace regarding the fair treatment of women.

(11) When a woman is pregnant, her workplace must provide her with necessary accommodations to perform her job.

(12) I am aware of studies that show women are penalized for being assertive at work in ways that men are not.

(13) I know about research that shows women's work opinions are not valued as much as men's. 
(14) I know about studies that show women at work are more likely to be interrupted while speaking than men are.

***Feel free to add any comments here with regards to the factor Knowledge as it relates to the construct allyhood in general.

\section{Factor 4: Social Support Skills}

Having the ability to support women who face sexism and sexist oppression in the workplace is another feature male allies of women at work should possess. Social Support refers to the ally's ability to actively listen, empathize and conduct an open dialogue (Jones et al., 2014; McIntosh, 1991; Washington \& Evans, 1991). An ally strong in this dimension would have well-developed interpersonal skills that offer warmth and trustworthiness to a member of the outgroup.

(1) I have developed the skills necessary to provide emotional support if a woman at work needs my help.

(2) If approached by a woman at work who was experiencing discrimination, I have the skills to be able to talk with her about it.

(3) I can listen to women's workplace concerns in a nonjudgmental way.

(4) I tune out women when they talk about fairness issues at work. (REVERSE)

(5) I understand why some women are offended by sexual jokes made at work.

(6) I am willing to have an open discussion about women's workplace issues.

(7) If a woman confides in me about sexism at work, I will not take advantage of her confidence. (8) I avoid having conversations with women about women's issues at work. (REVERSE) 
(9) I am able to actively listen to women at work who want to discuss work related concerns of fairness.

(10) I can sense when a woman at work wants to talk about how women are treated differently than men.

(11) I know how to be a trustworthy listener for women in my place of work.

***Feel free to add any comments here with regards to the factor Social Support

Skills as it relates to the construct allyhood in general.

\section{Factor 5: Instrumental Support Skills}

Instrumental Support Skills refers to being able to provide advice, guidance and information to another (McIntosh, 1991). Washington and Evans (1991) suggest that such support can be demonstrated by allies who possess the skills to direct another to appropriate resources. A strong ally in this dimension would be capable of providing advice/information to a woman at work, either directly or by steering her to helpful resources.

(1) Over the years I have learned how to advise a woman about her rights at work.

(2) I can direct a woman who may have a problem to the key people at work who may be of help.

(3) I am confident in my ability to detect subtle forms of sexism at work.

(4) I can direct a woman to outside resources (for example: books, Web sites, support groups, etc.) that support women's rights at work.

(5) I can refer women to outside organizations that advocate for women's rights at work. 
(6) I know about initiatives or offices in my organization that are dedicated to promoting and enforcing equal employment opportunities.

(7) I can recognize different forms of sexual harassment.

(8) I can assist a female coworker plan a course of action if she is experiencing a gender related workplace issue. (REVERSE.)

(9) I can advise a woman at work with regards to how to solve a gender related problem. ***Feel free to add any comments here with regards to the factor Instrumental Support as it relates to the construct allyhood in general.

\section{Factor 6: Action}

Taking direct action to support women and address sexism and sexist oppression in the workplace is another feature male allies of women at work should possess. Action refers to behavior that promotes the rights and social justice of the oppressed population in an effort to influence others. It may come in the form of behavioral interventions directed to ingroup members (confrontation) (Washington \& Evans, 1991) or as public

demonstrations of support to outgroup members in general, such as displaying symbols or supporting a women's organization (DiStefano et al., 2000). Keep in mind that emotional support for outgroup members on a specific, individual level is included in the third dimension of allyhood development (Social Support).

(1) I vote for issues that support women's rights at work.

(2) I encourage others to vote for issues that support women's rights at work.

(3) I have engaged in efforts to promote the equal treatment of women at work.

(4) I am a member of a group that promotes women's workplace rights.

(5) I display symbols that show my support for women's workplace rights. 
(6) If I see discrimination against a woman at work, I speak up.

(7) If I hear a slur or derogatory remark regarding women at work, I speak up.

(8) If I hear a dirty joke about women at work, I speak up.

(9) I avoid pointing out the ways in which women are treated at work. (REVERSE)

(10) I steer clear of discussions regarding the inequality of women at work. (REVERSE)

(11) If I knew a woman was being paid less than a man for the same job at my work, I would tell her.

(12) I engage in conversations with others regarding the importance of women's equality at work.

(13) If the discussion at work turns to the equal treatment women, I try to stay out of it. (REVERSE)

(14) I have taken a public stand on important issues facing women at work.

(15) I find ways to actively challenge my own biases and stereotypes about women at work.

(16) I voluntarily attend workshops or other programs to stay up-to-date on women's issues at work.

Feel free to add any comments here with regards to the factor Activism as it relates to the construct allyhood in general. 


\section{Appendix B}

\section{Item-to-Factor Matching Exercise}

for a Measure to Identify Men who are Allies of Women in the Workplace

Thank you for agreeing to assist with the validation of a list of items for a proposed measure to identify men who are allies of women in the workforce! The final version of this measurement will be administered to adult men who are employed.

Based on theories and measures of allyhood, such as LGBT allyhood (e.g., Broido, 2000; Jones, et al., 2014: Washington \& Evans, 1991), and research on sexism in the workplace (e.g., Leskinen, Cortina \& Kabat, 2011) we have developed six dimensions of allyhood development that assess various aspects of being a strong ally to women at work: (1) Distal Awareness, (2) Proximal Awareness, (3) Subjective Knowledge, (4) Social Support Skills, (5) Instrumental Support Skills, and (6) Action.

Currently, we are conceiving of these dimensions of allyhood as developing in parallel (though not perfectly independently). These six factors are NOT sequential steps of allyhood in a stage model; it is possible for an individual to have many combinations of high and low scores on these factors. Each factor may also have independent predictive value/validity, though higher scores on every factor are intended to indicate higher levels of the latent construct of "allyhood."

Overall, the purpose of the intended measure is to address the need for a tool to advance theory and practice on the nature, development, and utility of men as allies of women at work. With regard to academic research, such a tool would allow for the study of the moderating effects of allyhood on the relationship between predictors related to women's advancement (e.g., the proportion of women in an organization) and workplace outcomes (e.g., the proportion of women in leadership positions). Additionally, this measure would allow practitioners to identify allies for developmental purposes, for the formation of teams, and to evaluate the effectiveness of programs intended to increase allyhood and workplace climate for women.

One initial step in the validation of any scale is calling upon Subject Matter Experts (SMEs) to advise which items are likely to be associated with which factors. To that end we have devised a matching exercise where we will ask you to match items in the proposed scale with their expected factors.

You can find definitions of each of the 6 proposed factors in this document: Factor Explanations.docx. Feel free to refer to it throughout the exercise.

THANK YOU! 
Please use your mouse's drag and drop feature to move statements from the item column to a factor box. Click Factor Explanations.docx for a fuller discussion of each factor. If in your opinion according to the Factor Explanantions, an item does not belong to any of the listed factors, please move that item to the No Factor box.

Sampling of Various Items for SME Review (1) In general, women are not treated as favorably as men in the workplace.

(2) It is more difficult for women to advance in the workplace as compared to men.

(3) In general, women are paid less than men for the same job.

(4) At work, women are not compensated as much as men are.

(5) At work, women are not promoted as much as men are.

(6) Compared to women, I recognize that certain benefits at work come more easily to men.

(7) I believe women when they say there is sexism in the workplace.

(8) Sexism isn't a problem in modern-day organizations. (REVERSE)

(9) It's easier for a man to get to the top of an organization than it is for a woman, just because of his sex.

(10) Women face challenges at work that men do not.

(11) When a man and woman are equallyqualified for a position, the man's sex puts him at an advantage.

(12) Women experience sexual harassment at work more often than men.

(13) Despite the many advances made towards gender equality in the last 50 years, there is still prejudice against women in the workplace.

(14) Men are usually assumed to be competent in their jobs, while women usually have to prove their competence.
Distal Awareness (a general

understanding of male privilege in society)

Proximal Awareness (a man's personal understanding that he himself is a beneficiary of the patriarchy to some degree)

Subjective Knowledge (the ally's belief in his knowledge and understanding of how laws, policies, practices, histories, culture, and norms affect women as compared to men in the workplace)

Social Support (having the ability to support women who face sexism and sexist oppression in the workplace)

Instrumental Support Skills (being able to provide advice, guidance and information to another)

Action (taking direct action to support women and address sexism and sexist oppression)

No Factor - this item does not belong with any of the above factors. 


\section{APPENDIX C}

Descriptive Statistics for Seventeen Item M.A.W.W. from EFA

Item Content by Factor

$$
\text { Knowledge \& Awareness }
$$

2. I think women face barriers in the workplace that I do not.

Mean SD

18. Over the years I have learned how to point out places for women to research

$3.73 \quad 1.91$ about their rights at work.

7. Compared to women, I recognize that some benefits at work come more

3.721 .16
easily to men.

26. I am familiar with a number of laws that give women protection from unequal treatment at work.

17. When a woman is pregnant, her workplace must provide her with necessary accommodations to perform her job.

1. It is easier for a man to get to the top of an organization than it is for a woman because of sexism.

19. It is more difficult for women to advance in the workplace as compared to men.

31. I am familiar with studies that show women are penalized for being assertive at work in ways that men are not.

\section{Action}

42. I engage in conversations with others regarding the importance of women's equality at work.

39. If I see discrimination against a woman at work, I speak up against it.

30. At work, I wouldn't get into as much trouble if I talked down to a woman than if I had talked down to another man.

16. I steer clear of discussions regarding the inequality of women at work. (REVERSE)

6. I am a member of a group that promotes women's workplace rights.

\section{Skills \& Capacity}

59. I know about studies that show women at work are more likely to be interrupted while speaking than men are.

40. I can listen to women's workplace concerns in a nonjudgmental way.

22. If asked, I can direct a woman who may have a problem to the key people at work who may be of help.

46. If approached by a woman at work who was experiencing discrimination, I have the skills to be able to talk with her about it.

Note. $\mathrm{SD}=$ Standard Deviation. 


\section{Appendix D}

Interitem correlation matrix for the Seventeen Item M.A.W.W. from EFA.

\begin{tabular}{c|ccccccccccccccccc}
\hline Item No. & 22 & 40 & 46 & 9 & 1 & 2 & 7 & 17 & 18 & 19 & 31 & 6 & 16 & 39 & 42 & 26 & 30 \\
\hline 22 & 1.0 & .40 & .43 & .45 & .28 & .33 & .32 & .40 & .38 & .28 & .33 & .04 & .11 & .24 & .38 & .39 & .21 \\
40 & .40 & 1.0 & .40 & .36 & .30 & .32 & .35 & .24 & .42 & .30 & .27 & .06 & .06 & .34 & .23 & .33 & .26 \\
46 & .43 & .40 & 1.0 & .35 & .24 & .28 & .32 & .30 & .29 & .24 & .27 &. .01 & .01 & .13 & .16 & .30 & .23 \\
59 & .45 & .36 & .35 & 1.0 & .21 & .21 & .23 & .21 & .27 & .18 & .17 & -.04 & .07 & .15 & .27 & .19 & .09 \\
1 & .28 & .30 & .24 & .21 & 1.0 & .78 & .74 & .77 & .75 & .67 & .63 & .22 & .12 & .32 & .14 & .78 & .31 \\
2 & .33 & .32 & .28 & .2 & .78 & 1.0 & .71 & .75 & .72 & .62 & .57 & .17 & .03 & .26 & .06 & .73 & .27 \\
7 & .32 & .35 & .32 & .2 & .74 & .71 & 1.0 & .70 & .66 & .64 & .59 & .21 & .11 & .27 & .10 & .72 & .25 \\
17 & .40 & .24 & .30 & .21 & .77 & .75 & .70 & 1.0 & .75 & .67 & .69 & .16 & .10 & .31 & .10 & .80 & .31 \\
18 & .38 & .42 & .29 & .27 & .75 & .72 & .66 & .75 & 1.0 & .67 & .65 & .18 & .12 & .32 & .11 & .78 & .34 \\
19 & .28 & .30 & .24 & .18 & .67 & .62 & .64 & .67 & .67 & 1.0 & .63 & .35 & .15 & .37 & .05 & .73 & .35 \\
31 & .33 & .27 & .27 & .17 & .63 & .57 & .59 & .69 & .65 & .63 & 1.0 & .21 & .09 & .34 & .08 & .66 & .32 \\
6 & .04 & .06 & -.01 & -.04 & .22 & .17 & .21 & .16 & .18 & .35 & .21 & 1.0 & .47 & .40 & .27 & .23 & .44 \\
16 & .11 & .06 & .01 & .07 & .12 & .03 & .11 & .10 & .12 & .15 & .09 & .47 & 1.0 & .51 & .43 & .17 & .54 \\
39 & .24 & .34 & .13 & .15 & .32 & .26 & .27 & .31 & .32 & .37 & .34 & .40 & .51 & 1.0 & .45 & .30 & .58 \\
42 & .38 & .23 & .16 & .27 & .14 & .06 & .10 & .10 & .11 & .05 & .08 & .27 & .43 & .45 & 1.0 & .11 & .43 \\
26 & .39 & .33 & .30 & .19 & .78 & .73 & .72 & .80 & .78 & .73 & .66 & .23 & .17 & .30 & .11 & 1.0 & .35 \\
30 & .21 & .26 & .23 & .09 & .31 & .27 & .25 & .31 & .34 & .35 & .32 & .44 & .54 & .58 & .43 & .35 & 1.0 \\
\hline
\end{tabular}




\section{Appendix E}

Descriptive Statistics for Fifteen Item M.A.W.W. from CFA

Item Content by Factor

Mean SD

Knowledge \& Awareness

17. When a woman is pregnant, her workplace must provide her with necessary

$4.21 \quad .56$ accommodations to perform her job.

2. I think women face barriers in the workplace that I do not.

$4.01 \quad .69$

7. Compared to women, I recognize that some benefits at work come more easily to men.

26. I am familiar with a number of laws that give women protection from unequal treatment at work.

1. It is easier for a man to get to the top of an organization than it is for a woman because of sexism.

men.

31. I am familiar with studies that show women are penalized for being assertive at work in ways that men are not.

\section{Action}

39. If I see discrimination against a woman at work, I speak up against it.

42. I engage in conversations with others regarding the importance of women's equality at work.

6. I am a member of a group that promotes women's workplace rights.

16. I steer clear of discussions regarding the inequality of women at work. (REVERSE)

40. I can listen to women's workplace concerns in a nonjudgmental way.

46. If approached by a woman at work who was experiencing discrimination, I have the skills to be able to talk with her about it.

22. If asked, I can direct a woman who may have a problem to the key people at work who may be of help.

59. I know about studies that show women at work are more likely to be interrupted while speaking than men are. 


\section{Appendix F}

Interitem correlations for the Fifteen Item M.A.W.W. from CFA

\begin{tabular}{c|ccccccccccccccc}
\hline Item No. & 22 & 40 & 46 & 9 & 1 & 2 & 7 & 17 & 19 & 31 & 6 & 16 & 39 & 42 & 26 \\
\hline 22 & 1.0 & .40 & .43 & .45 & .28 & .33 & .32 & .40 & .28 & .33 & .04 & .11 & .24 & .38 & .39 \\
40 & .40 & 1.0 & .40 & .36 & .30 & .32 & .35 & .24 & .30 & .27 & .06 & .06 & .34 & .23 & .33 \\
46 & .43 & .40 & 1.0 & .35 & .24 & .28 & .32 & .30 & .24 & .27 & -.01 & .01 & .13 & .16 & .30 \\
59 & .45 & .36 & .35 & 1.0 & .21 & .21 & .23 & .21 & .18 & .17 & -.04 & .07 & .15 & .27 & .19 \\
1 & .28 & .30 & .24 & .21 & 1.0 & .78 & .74 & .77 & .67 & .63 & .22 & .12 & .32 & .14 & .78 \\
2 & .33 & .32 & .28 & .2 & .78 & 1.0 & .71 & .75 & .62 & .57 & .17 & .03 & .26 & .06 & .73 \\
7 & .32 & .35 & .32 & .2 & .74 & .71 & 1.0 & .70 & .64 & .59 & .21 & .11 & .27 & .10 & .72 \\
17 & .40 & .24 & .30 & .21 & .77 & .75 & .70 & 1.0 & .67 & .69 & .16 & .10 & .31 & .10 & .80 \\
19 & .28 & .30 & .24 & .18 & .67 & .62 & .64 & .67 & 1.0 & .63 & .35 & .15 & .37 & .05 & .73 \\
31 & .33 & .27 & .27 & .17 & .63 & .57 & .59 & .69 & .63 & 1.0 & .21 & .09 & .34 & .08 & .66 \\
6 & .04 & .06 & -.01 & -.04 & .22 & .17 & .21 & .16 & .35 & .21 & 1.0 & .47 & .40 & .27 & .23 \\
16 & .11 & .06 & .01 & .07 & .12 & .03 & .11 & .10 & .15 & .09 & .47 & 1.0 & .51 & .43 & .17 \\
39 & .24 & .34 & .13 & .15 & .32 & .26 & .27 & .31 & .37 & .34 & .40 & .51 & 1.0 & .45 & .30 \\
42 & .38 & .23 & .16 & .27 & .14 & .06 & .10 & .10 & .05 & .08 & .27 & .43 & .45 & 1.0 & .11 \\
26 & .39 & .33 & .30 & .19 & .78 & .73 & .72 & .80 & .73 & .66 & .23 & .17 & .30 & .11 & 1.0 \\
\hline
\end{tabular}


VITA

\title{
EDWARD JOSEPH SULLIVAN
}

\author{
Born, Kansas City, Missouri
}

1987

B.S., Chemistry, Creighton University

Omaha, Nebraska

1993

J.D., University of Georgia

Athens, Georgia

1993

Moot Court International Law National Champion

2013

M.S., Industrial and Organizational Psychology

Florida International University

Miami, Florida

$2014-2019$

Teaching Assistant

Florida International University

Miami, Florida

$2018-2019$

Doctoral Candidate

Florida International University

Miami, Florida

\section{PUBLICATIONS AND PRESENTATIONS}

Rudolph, C. W., \& Sullivan, E. J. (2013). Perceived leadership potential as a function of perceived age and physical attractiveness. In L. Finkelstein, New exploration of age effects at work, Symposium conducted at the meeting of European Association of Work and Organizational Psychology, Munich, Germany.

Sullivan, E.J., Viswesvaran, C., \& Eaton, A. (2018, April). Are I/O practices and the legal system in sync? Poster session presented at the Annual Convention of the Society of Industrial and Organizational Psychology.

Sullivan, E.J., \& Eaton, A. (2019, June). The development and validation of a measure to identify men who are allies to women in the workplace. Scheduled symposium presentation at the Annual Convention of Society for the Psychological Study of Social Issues. 